\title{
Macrophage Function in the Pathogenesis of Non-alcoholic Fatty Liver Disease: The Mac Attack
}

\author{
Jarren R. Oates ${ }^{1,2,3}$, Melanie C. McKell ${ }^{1,3,4}$, Maria E. Moreno-Fernandez ${ }^{1,2}$, \\ Michelle S. M. A. Damen ${ }^{1,2}$, George S. Deepe Jr. ${ }^{5}$, Joseph E. Qualls ${ }^{1,3,4}$ and \\ Senad Divanovic ${ }^{1,2,3,6 *}$
}

${ }^{1}$ Department of Pediatrics, University of Cincinnati College of Medicine, Cincinnati, $\mathrm{OH}$, United States, ${ }^{2}$ Division of Immunobiology, Cincinnati Children's Hospital Medical Center and the University of Cincinnati College of Medicine, Cincinnati, $\mathrm{OH}$, United States, ${ }^{3}$ Immunology Graduate Program, Cincinnati Children's Hospital Medical Center and the University of Cincinnati College of Medicine, Cincinnati, OH, United States, ${ }^{4}$ Division of Infectious Diseases, Cincinnati Children's Hospital Medical Center and the University of Cincinnati College of Medicine, Cincinnati, OH, United States, ${ }^{5}$ Department of Medicine, University of Cincinnati College of Medicine, Cincinnati, OH, United States, ${ }^{6}$ Center for Inflammation and Tolerance, Cincinnati Children's Hospital Medical Center, Cincinnati, OH, United States

OPEN ACCESS

Edited by:

Ralf Weiskirchen,

RWTH Aachen University, Germany

Reviewed by:

Giovanni Tarantino,

University of Naples Federico II, Italy

Lionel Hebbard

James Cook University, Australia

*Correspondence:

Senad Divanovic

senad.divanovic@cchmc.org

Specialty section

This article was submitted to

Molecular Innate Immunity,

a section of the journal

Frontiers in Immunology

Received: 05 October 2019 Accepted: 26 November 2019 Published: 12 December 2019

Citation:

Oates JR, McKell MC, Moreno-Fernandez ME, Damen MSMA, Deepe GS Jr, Qualls JE and Divanovic S (2019) Macrophage

Function in the Pathogenesis of Non-alcoholic Fatty Liver Disease: The Mac Attack. Front. Immunol. 10:2893. doi: 10.3389/fimmu.2019.02893
Obesity is a prevalent predisposing factor to non-alcoholic fatty liver disease (NAFLD), the most common chronic liver disease in the developed world. NAFLD spectrum of disease involves progression from steatosis (NAFL), to steatohepatitis (NASH), cirrhosis and hepatocellular carcinoma (HCC). Despite clinical and public health significance, current FDA approved therapies for NAFLD are lacking in part due to insufficient understanding of pathogenic mechanisms driving disease progression. The etiology of NAFLD is multifactorial. The induction of both systemic and tissue inflammation consequential of skewed immune cell metabolic state, polarization, tissue recruitment, and activation are central to NAFLD progression. Here, we review the current understanding of the above stated cellular and molecular processes that govern macrophage contribution to NAFLD pathogenesis and how adipose tissue and liver crosstalk modulates macrophage function. Notably, the manipulation of such events may lead to the development of new therapies for NAFLD.

\section{Keywords: macrophage, metabolism, NAFLD, inflammation, cytokines}

\section{INTRODUCTION}

The unabated obesity pandemic is directly linked with the incidence of non-alcoholic fatty liver disease (NAFLD). NAFLD afflicts $\sim 35 \%$ of obese individuals worldwide $(1,2)$. Current epidemiological estimates suggest that NAFLD will soon surpass chronic hepatitis C infection as the leading cause of liver transplantation. Given the lack of effective therapies for NAFLD, costs of care and management of associated symptoms come with a considerable economic burden (3).

NAFLD spectrum of disease progresses from non-alcoholic fatty liver (NAFL) or hepatic steatosis, to non-alcoholic steatohepatitis (NASH), to cirrhosis and hepatocellular carcinoma (HCC). Steatosis is characterized by increased macrovesicular and microvesicular lipid droplet accumulation that occurs in more than $5 \%$ of hepatocytes $(1,2,4)$. Approximately $25 \%$ of individuals afflicted with NAFL progress to NASH (1). NASH is characterized by hepatocellular ballooning, in part due to increased immune cell infiltration, activation, and proinflammatory cytokine production (4-6). These mechanisms coupled with others such as adipokine production 
and activation of endoplasmic reticulum stress and reactive oxygen species (ROS) promote hepatic fibrosis and progression to cirrhosis and $\operatorname{HCC}(7,8)$.

The contribution of various immune cells in hepatic inflammation and the mechanisms that govern their migration to the liver, polarization, and inflammatory capabilities, in NAFLD progression represent an intense area of investigation. Here, we specifically focus on the contribution of macrophages to NAFLD pathogenesis. We review the landscape of underlying mechanisms that regulate macrophage effector functions and macrophage interplay with other immune cells/tissues/organs which collectively contribute to NAFLD progression.

\section{CURRENT KNOWLEDGE AND DISCUSSION}

\section{Immune Responses in NAFLD}

Dysregulated immune responsiveness is central to the development and progression of $\operatorname{NAFLD}(9,10)$. In obesity, both liver resident (e.g., Kupffer cells, [KC], hepatic stellate cells, [HSC], hepatocytes) and infiltrating immune cells (e.g., neutrophils, dendritic cells [DC], natural killer [NK] cells, NKT cells, blood monocytes, T cells, B cells, and macrophages) contribute to NAFLD development and progression via systemic and tissue inflammatory mediator production (e.g., interleukin [IL]-17A, IL-6, tumor necrosis factor [TNF], IL-1 $\beta) \quad(5,11)$. Obesity-associated intestinal permeability and augmented circulating levels of inflammatory ligands (e.g., lipopolysaccharide [LPS]) (12) via activation of pattern recognition receptors (PRRs) on hematopoietic and nonhematopoietic cells activate multiple proinflammatory cascades that in unison promote liver injury (13). The contribution of PRRs to NAFLD progression has been reviewed in detail elsewhere $(14,15)$. PRR signaling in macrophages, also contributes to activation of adaptive immune responses, with macrophage- $\mathrm{T}$ cell interplay having a particularly important role in NAFLD progression (16). In this setting, activated, liver infiltrating $\mathrm{T}$ cells produce proinflammatory cytokines and amplify macrophage polarization and activation to in turn propagate overall hepatic inflammation, hepatocellular damage and hepatocyte release of damage associated molecular patterns (DAMPs). Cumulatively these processes fuel and support a chronic inflammatory state in the liver that is a hallmark of NAFLD progression. Due to the extent of various immune processes in NAFLD, here we selectively focus on the role of macrophage-mediated inflammation and their contribution to NAFLD pathology. The contribution of other immune cells (e.g., T cells, neutrophils, DC, NK cells, and NKT cells) and cytokines in NAFLD has been discussed elsewhere $(14,17,18)$.

\section{Macrophage Recruitment to the Liver}

Liver infiltration by inflammatory monocytes/macrophages is associated with NAFLD progression (19). Increased release of free fatty acid (FFA) by white adipose tissue (WAT) augments triglyceride synthesis and storage in hepatocytes and induces hepatocyte release of inflammatory mediators including proinflammatory cytokines and macrophage recruiting chemokines (e.g., CCL2, CXCL10) (20, 21). In addition to hepatocytes, HSCs, myofibroblast and macrophages themselves can also produce various chemokines (e.g., CCL2, CCL3, CCL4, CCL5, CCL8, and CXCL10) to fuel increased macrophage recruitment (22).

The contribution of hepatic macrophage recruitment to NAFLD pathogenesis is supported in part by increased systemic and hepatic chemokine levels in NAFLD progression in humans (23). One of the most widely explored pathways of recruiting inflammatory and fibrogenic monocytes to the injured liver is the CCR2/CCL2 axis (24). Pharmacological inhibition of CCR2 and genetic deletion of CCL2 reduced liver steatosis in obese mice (25-27). Additionally, use of CCR1-, CCR2-, CCR5-, and CCR8-deficient mice or pharmacological inhibition of these axes reduced hepatic macrophage infiltration, hepatic fibrosis, and hepatocellular damage in experimental models of chronic liver injury (28-32). Recent evidence also suggests that CXCR3deficient mice are protected from macrophage infiltration and hepatocellular damage in obesity $(33,34)$. Further, CXCL10deficient mice exhibit reduced NAFL (34). Despite its promising effects in animal models, targeting of the CCR2 axis in human NALFD using Cenicriviroc (CVC) did not impact hepatic lobular inflammation and only mildly improved fibrosis and decreased circulating levels of sCD14 (a marker of monocyte activation) (35). Characterization of the intrahepatic immune cells will be required to elucidate the effects of CVC on immune cells, monocyte and macrophage recruitment and fibrogenesis. The results of such could give insight to observed difference of effects of CVC on NAFLD progression between murine models and humans.

Like chemokines, inflammatory cytokines can also alter macrophage activation and tissue recruitment in NAFLD. For example, the IL-17A axis impacts macrophage recruitment in the liver (36), while IL-17RA depletion on macrophages ameliorates NAFLD severity (37). However, as IL-17A can also activate liver parenchymal cells to modulate macrophage recruitment. Thus, detailed studies focused on the role of IL-17 family members, their cognate receptors and cell specific expression in NAFLD pathogenesis are needed. The overall role of the IL-17 axis in NAFLD pathogenesis has been reviewed in detail elsewhere (18).

\section{Macrophage Subsets}

KCs reside in the anatomical areas that receive venous blood from the gut including hepatic sinusoids, hepatic lymph nodes and portal tract (38). Approximately $80 \%$ of the liver blood supply comes from the gut via the portal vein (39). As such, KCs act as key sentinels of the gut-liver interface. Under homeostatic conditions, PRR signaling instructs $\mathrm{KCs}$ to govern liver immunity by maintaining tolerance to harmless immunogens and cellular debris while in parallel enabling them to mount a response against pathogenic invaders via phagocytosis, cytokine production and antigen presentation. Collectively, the adaptation to latter events is central to preventing dissemination of microbes into peripheral circulation $(5,39,40)$. In obesity, increased intestinal permeability, trafficking of bacteria into the gut lumen and LPS sensing $(2,40,41)$ fuel $\mathrm{KC}$ activation and alter their function (42). In this context, activated KCs favor inflammatory 
responses that contribute to NAFLD pathogenesis (13). In vitro treatment of KCs with FFAs (e.g., palmitate) promotes activation and secretion of inflammatory cytokines (e.g., IL-6, TNF, IL-1 $\beta$ ) (43) while KC depletion in vivo protects from obesity-driven hepatic steatosis (13).

Common bone marrow myeloid progenitors give rise to granulocyte-macrophage progenitors (GMP) from which monocytes are derived. Upon egression from the bone marrow, and following hepatic inflammatory insult, circulating monocytes traffic to the liver. Once in the liver, in response to cytokines and various pathogen associated molecular patterns (PAMPs)/DAMPs, monocytes activate unique transcriptional profiles and differentiate into macrophages. In response to IFN $\gamma$ or PRR signaling, recruited monocytes differentiate into "classically" activated macrophages that produce proinflammatory cytokines (e.g., IL-6, TNF, IL-1 $\beta$, IL-12), drive liver recruitment of various immune cells and enhance the overall hepatic inflammation $(5,13,44)$. Conversely, in response to either IL-4 or IL-13, tissue recruited monocytes differentiate into "alternatively" activated macrophages that produce anti-inflammatory and wound healing mediators (e.g., IL-8, MCP-1, IL-10) $(38,45,46)$. The overall balance of "classically" and "alternatively" activated macrophages in the liver regulates hepatic inflammation, liver scarring and fibrosis. Targeting of inflammatory signaling pathways in macrophages via deletion of JNK, IKK $\beta$, or Toll-like receptor (TLR) 4 is sufficient to reduce hepatic steatosis and inflammation (47-49). A brief summary of the above discussed processes is depicted in Figure 1.

\section{Macrophages and Proinflammatory Cytokine Production}

Macrophage produced cytokines (e.g., IL-6, TNF, IL-1 $\beta$ ) can directly target hepatocytes and promote steatosis, inflammation and hepatocellular damage (5). Systemic increase of these proinflammatory cytokines positively correlates with hepatocellular damage in humans and is recapitulated in NAFLD experimental mouse models $(50,51)$.

IL-6 is a multifunctional cytokine that regulates immune responses, acute phase reactions, hematopoiesis, and plays key roles in inflammation, host defense and tissue injury $(52,53)$. IL-6 stimulates hepatic lipogenesis (54), and is associated with obesity (55), impaired insulin signaling $(56,57)$, and altered insulin sensitivity by activating key steps in the insulin signaling pathway (58). IL-6 is also a biomarker of insulin resistance and cardiovascular diseases risk $(50,59,60)$. In humans with $\mathrm{NASH}$, there is a positive correlation between IL-6 expression in hepatocytes and the severity of NAFLD (61). IL-6-deficient mice display a milder NAFLD severity and antibody mediated IL-6 receptor (IL-6R) neutralization improved liver damage in mice fed methionine choline deficient (MCD) diet, despite enhanced steatosis $(51,62)$.

TNF stimulates hepatic fatty acid synthesis (FAS), increases serum triglyceride (TG) levels (63), stimulates very low density lipoprotein (VLDL) production from liver and contributes to impaired insulin signaling $(64,65)$. TNF also activates harmful proatherogenic pathways via the reduction of highdensity lipoprotein (HDL)-cholesterol, elevated expression of cholesterogenic genes, accompanied by an increase in potentially harmful precholesterol metabolites, and suppression of cholesterol elimination (66). Thus, it is not surprising that TNF sensing by hepatocytes promotes hepatocyte cell death and hepatocyte proliferation (67), and as such directly contributes to NAFLD pathogenesis (68). Further, deletion of TNF in experimental mouse models of NAFLD correlates with decreased steatosis, fibrosis and improved glucose tolerance (69).

IL-1 $\beta$ promotes liver steatosis, inflammation and fibrosis via activation of the IL-1 receptor (IL-1R) signaling (70). IL-1 $\beta$ stimulates TG and cholesterol accumulation in hepatocytes and as such contributes to the development of hepatic steatosis (71). Mechanistically, IL-1 $\beta$ also promotes liver inflammation by inducing IL- 6 production, upregulating ICAM-1 and neutrophil infiltration and accrual in the liver (72). IL-1R-deficient mice are protected from liver fibrosis (73). Hepatocyte-specific deletion of IL-1R attenuates liver injury in a model of acute liver disease (74). Whether similar effects are observed in animal models of NAFLD have not been examined. Further, IL-1R activates Myd88 signaling similar to TLRs (75). Thus, the role of IL-1R signaling in NAFLD warrants further investigation. In addition, blockade of IL-1 signaling with anakinra improved glycemic control in patients with T2D (76), suggesting the importance of inflammatory mediators in liver disease pathogenesis.

\section{Macrophages and ROS Production}

Reactive oxygen species (ROS) production, a central antimicrobial effector function of macrophages, can be induced in part via macrophage sensing of proinflammatory cytokines. Macrophages generate ROS via numerous mechanisms including ER stress, mitochondrial damage and activation of nicotinamide adenine dinucleotide phosphate (NADPH) oxidases (NOXs). NOX2, also known as the phagocytic nicotinamide adenine dinucleotide phosphate NADPH oxidase, is constitutively associated with p22phox at the plasma membrane. PRR signaling in KCs and infiltrating macrophages causes complexing of NOX2 with other proteins (p67, P40, Rac GTPases) to generate superoxide, drive proinflammatory cytokine production (e.g., IL-6, TNF, IL-1 $\beta$, transforming growth factor- $\beta$ [TGF $\beta]$ ) and promote hepatic steatosis, hepatocellular damage and fibrosis $(43,77,78)$. NOX2-deficient mice display reduced macrophage-associated proinflammatory cytokine production, hepatic steatosis and fibrosis, and overall NAFLD severity in obesity $(43,79,80)$. However, the underlying mechanisms regulating macrophage ROS production in NAFLD are not fully understood. Thus, in depth interrogation of the interplay between inflammatory cytokines and NADPH components on macrophage ROS production in NAFLD progression is needed.

\section{Macrophage Cellular Metabolism}

Metabolic pathways regulate immune cell function and inflammation $(81,82)$. Obesity alters cellular metabolism (83). In fact, both obesity-associated and inflammation-driven derangements in cellular metabolism are implicated in NAFLD 


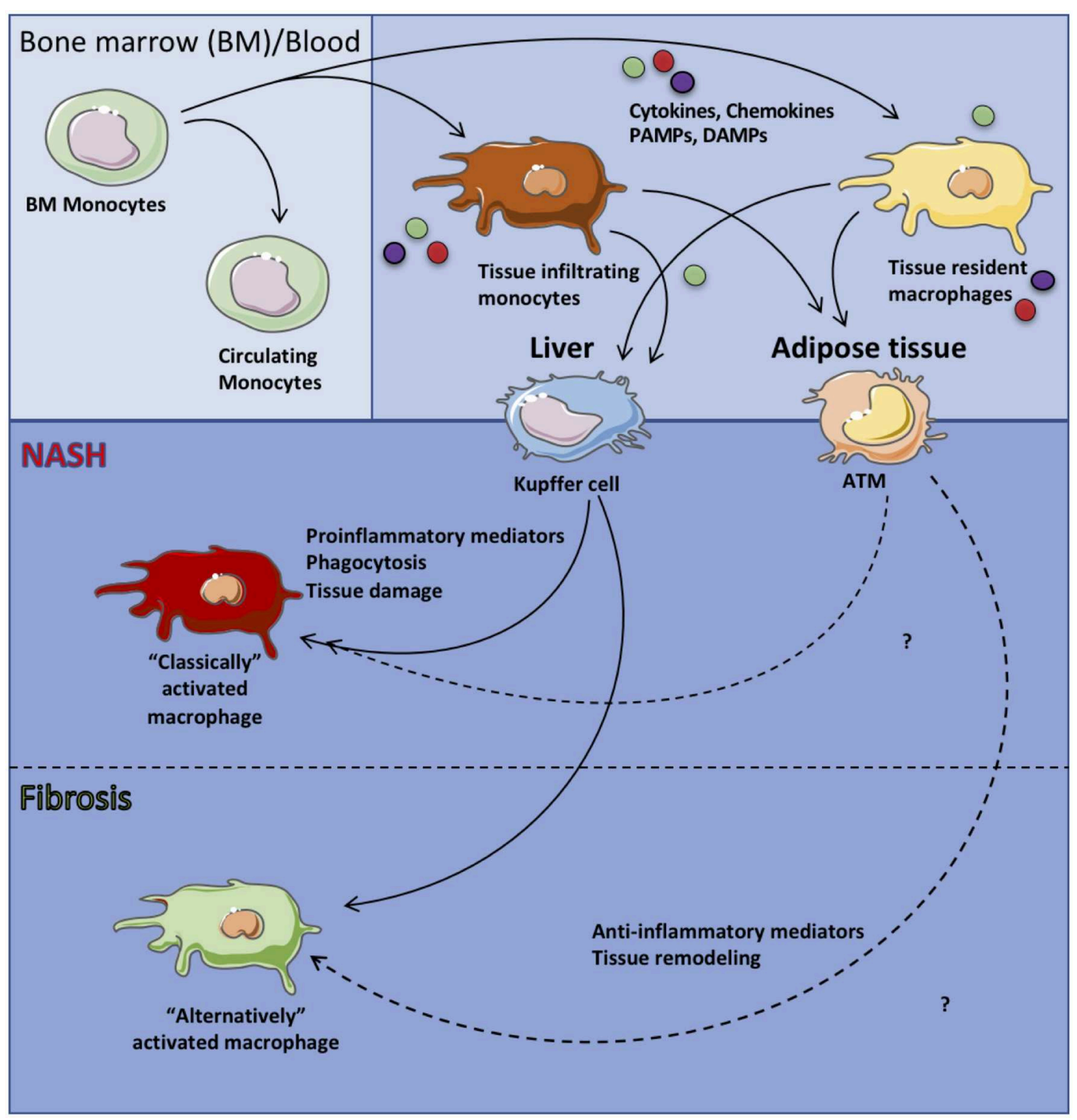

FIGURE 1 | Macrophage subsets in health and disease. Circulating monocytes originating from the bone marrow are recruited to specific tissues and differentiate into tissue resident macrophages. In the context of systemic inflammation, circulating monocytes as well as tissue resident macrophages are activated by sensing of proinflammatory mediators (i.e., IL-6, TNF, IL-1 $\beta$ ), chemokines and ROS or anti-inflammatory mediators (i.e., IL-10) leading to "classically" or "alternatively" activated tissue macrophages, respectively which then contribute to tissue pathology.

progression (84-86). The full discovery of specific metabolic pathways and genes detrimental to NAFLD pathogenesis however remains an intense area of investigation. Macrophagedriven inflammation and resolution of inflammation are intricately linked to various metabolic pathways and several clinical phenotypes (i.e., insulin resistance, hyperlipidemia, etc.) $(86,87)$. Here we review metabolic pathways that contribute to macrophage-intrinsic inflammation and resolution in NAFLD. A brief summary of these processes is depicted in Figure 2 and Table 1.

\section{Glycolysis}

Macrophage reliance on glycolysis to meet energetic demands has been demonstrated in several murine models of "classical" macrophage activation (88). Upon stimulation with cytokines or activation of PRR signaling, macrophages acquire a proinflammatory phenotype that correlates with robust upregulation of glycolytic pathways including hypoxia inducing factor alpha (HIF1 $\alpha)$ (88). Activation of HIF1 $\alpha$ induces transcription of hypoxic genes (e.g., glucose transporters, glycolytic genes) and IL-1 $\beta$ production by macrophages. 


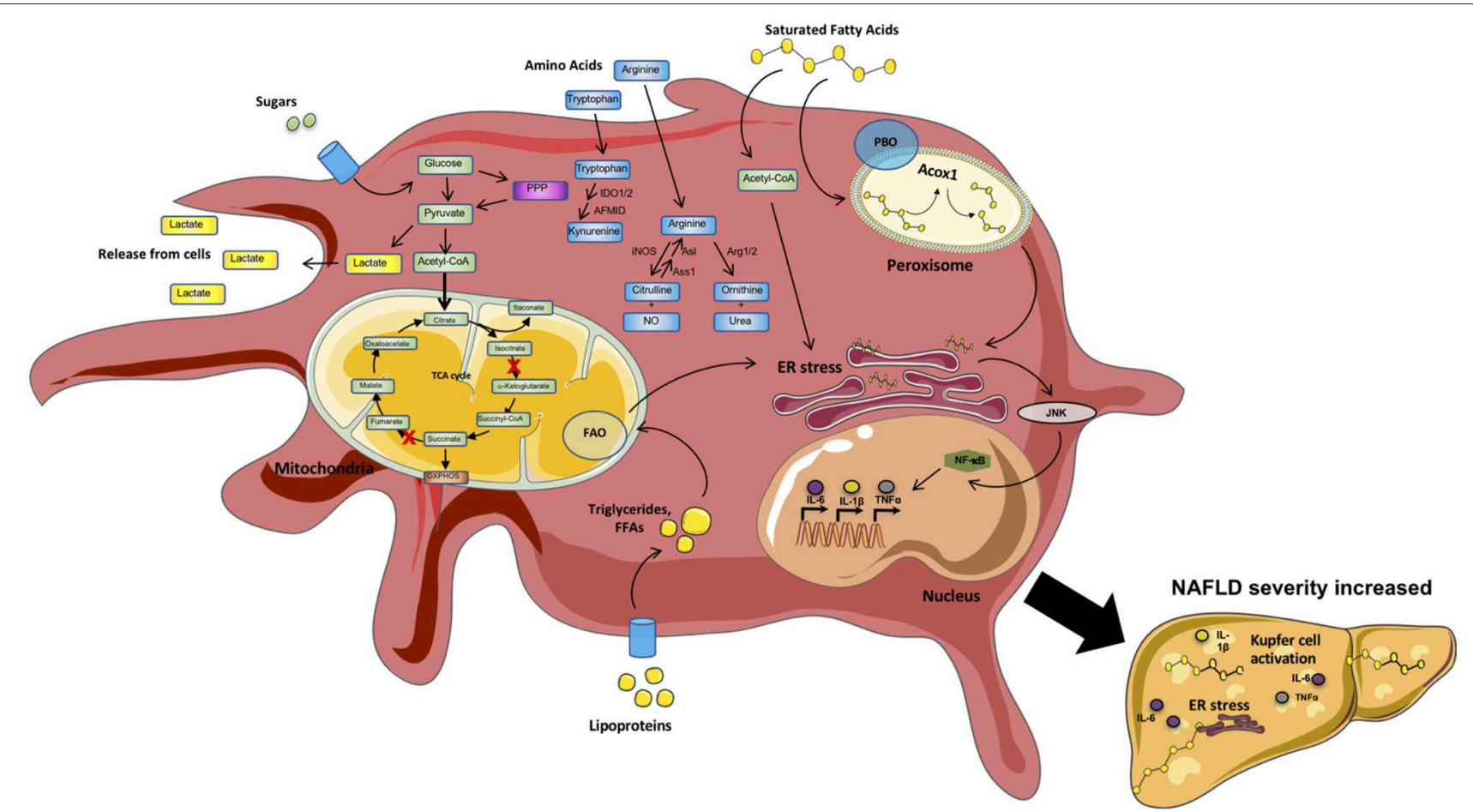

FIGURE 2 | Metabolic processes within inflammatory macrophages. Macrophages are highly metabolically active cells. Their metabolic identity is impacted by inflammatory mediators. In contrast, specific metabolic pathways (Fatty acid synthesis [FAS], Glycolysis, Amino acid [AA] metabolism) regulate the type of mediators produced by these cells. During a proinflammatory state, inflammatory mediators (e.g., sugars, lipoproteins, saturated fatty acids [SFAs], cytokines [IL6, TNF]) trigger "classical" activation of circulating and tissue resident macrophages (e.g., Kupfer cells and adipose tissue macrophages [ATMs]). Circulating sugars are taken up and processed via glycolysis/TCA cycle. In addition, several intermediate metabolites, as well as amino acids L-arginine, L-tryptophan and glutamine, can impact macrophage effector functions. Sensing/uptake of excessive lipoproteins and SFAs activates the mitochondrial fatty acid oxidation (FAO) and peroxisomal fatty acid beta-oxidation (PBO) pathways to breakdown long chain and very long chain fatty acids, respectively. Excessive activation of these pathways triggers ER stress and signaling via JNK and NF-kB, resulting in amplified production of proinflammatory mediators. "Classical" macrophage activation shifts the cells toward preferential utilization of glycolytic pathways with altered enzyme activity within the tricarboxylic acid cycle (TCA) cycle generating more lactate and fast energy production in the form of ATP to generate inflammatory mediators (e.g., IL-6, TNF, IL1). Metabolism of tryptophan (L-TRP) and arginine (L-ARG) by macrophages regulates key immunologic processes. Cumulatively, these inflammatory mechanisms fuel the overall systemic and tissue inflammation, hepatocyte death, and fibrosis in turn amplifying NAFLD pathogenesis.

TABLE 1 | Metabolic function in macrophage subsets.

\begin{tabular}{|c|c|c|}
\hline Pathway & "Classically" activated macrophage & "Alternatively" activated macrophage \\
\hline Reactive oxygen species & $\begin{array}{l}\text { Increased ROS production through mitochondrial ROS and } \\
\text { NADPH oxidase }\end{array}$ & Mitochondrial ROS and NADPH oxidase activity minimal \\
\hline Pentose phosphate pathway & Increased pentose phosphate pathway & Decreased pentose phosphate pathway \\
\hline Tricarboxylic Acid Cycle & Fractured TCA cycle, broken at Idh and Sdh & $\begin{array}{l}\text { Functional TCA cycle fed by acetyl-coA from beta-oxidation and } \\
\text { glycolysis }\end{array}$ \\
\hline Fatty acid & Fatty acid synthesis from fractured TCA & Fatty acid beta-oxidation from lipoproteins \\
\hline L-Tryptophan catabolism & $\begin{array}{l}\text { L-Tryptophan catabolism by IDO results in suppression of } \\
\text { aberrant inflammation }\end{array}$ & L-Tryptophan catabolism not induced \\
\hline L-Arginine metabolism & $\begin{array}{l}\text { L-Arginine metabolism by iNOS resulting in nitric oxide } \\
\text { production }\end{array}$ & $\begin{array}{l}\text { L-Arginine metabolism by arginase resulting in L-ornithine and } \\
\text { downstream metabolites }\end{array}$ \\
\hline
\end{tabular}

ATP, adenosine triphosphate; Idh, isocitrate dehydrogenase; IDO, indoleamine-2,3-dioxygenase; iNOS, inducible nitric oxide synthase; NADPH, nicotinamide adenine dinucleotide phosphate; ROS, reactive oxygen species; Sdh, succinate dehydrogenase; TCA, tricarboxylic acid. Unless noted, references are in main text. *Arginase 1 (Arg1) expression occurs along with iNOS in macrophages during intracellular infection, and is not sufficient on its own to define alternative activation. 
Preferential skewing toward glycolysis favors proinflammatory macrophage effector functions as administration of the glucose analog, 2-deoxyglucose (2-DG), decreases macrophage inflammatory polarization, cytokine production and phagocytosis (88). Mice fed MCD diet and patients with NASH display increased hepatic macrophage HIF1 $\alpha$ expression and exacerbated hepatic steatosis and inflammation (89). However, given the functional relevance of HIF $1 \alpha$ to macrophage-mediated inflammation, additional studies are warranted to determine the impact of macrophage-intrinsic HIF1 $\alpha$ in inflammation and NAFLD progression.

\section{Pentose Phosphate Pathway}

Pentose phosphate pathway (PPP) branches off glycolysis at glucose-6-phosphate, the second step in glycolysis. Through a series of dehydration and decarboxylation reactions, glucose-6phosphate is converted to ribulose-5-phosphate. Macrophages upregulate the PPP in response to LPS, which yields two NADPH (used as cofactors for NOXs) and in turn promote inflammation and cellular damage (90-92). Additionally, the PPP is necessary for limiting the dissemination of various pathogens (93). In contrast, macrophages also use the PPP to resolve inflammation and ROS, as PPP results in glutathione reduction and subsequently maintains proper redox balance, limiting the consequences of extraneous ROS activity $(94,95)$. During hypercholesterolemia, cholesterol inhibits LPS-mediated PPP activity in inflammatory macrophages, leading to a foamy macrophage phenotype (96). Further, adipocytes are known to use NADPH metabolism to regulate lipid metabolism, and dysregulation of enzymes involved in the production of NADPH contributes to obesity and obesity-related pathology $(97,98)$. Despite the role of PPP in modulating inflammation, the contribution of this metabolic pathway to macrophage-intrinsic inflammation in the context of NAFLD is underdefined and requires in-depth examination.

\section{Tricarboxylic Acid Cycle}

Acetyl CoA, generated following glycolysis or beta-oxidation, enters the tricarboxylic acid (TCA) cycle, resulting in $\mathrm{H}_{2} \mathrm{O}, \mathrm{CO}_{2}$, $\mathrm{NADH}$ and $\mathrm{FADH}_{2}$ generation. The latter two are utilized in the electron transport chain (ETC) to produce ATP. Despite the high energy yield of the TCA cycle, the process is time consuming and requires oxygen. In the context of a rapid inflammatory response, the TCA is downregulated and fractured in macrophages. Specifically, inflammatory macrophages reduce isocitrate dehydrogenase (Idh) and succinate dehydrogenase (Sdh) activity $(90,91)$. This results in decreased $\alpha$-ketoglutarate formation but increased production of itaconate - a key antimicrobial metabolite. Accumulation of succinate in macrophages can inhibit the HIF1 $\alpha$-suppressing molecules prolyl hydroxylases (PHDs), allowing HIF $1 \alpha$ to drive IL- $1 \beta$ and other inflammatory processes (90). Sdh is complex II of the ETC, which donates two electrons from $\mathrm{FADH}_{2}$ to produce the electron gradient that drives ATP synthesis. During LPS stimulation, the breakdown of Sdh feeds electrons through complex I, known as reverse electron transport, resulting in mitochondrial ROS production (99). The contribution of Idh and Sdh to NAFLD has not been investigated.
However, it can be hypothesized that the hepatic inflammatory environment in NAFLD would drive the breakdown of the TCA cycle, as seen in LPS stimulated macrophages. Hence, additional studies are needed to formally address these postulates.

\section{Fatty Acid Synthesis (FAS)}

Excessive hepatocellular uptake of glucose is diverted to FAS pathways where glucose is converted into TGs and secreted to adipose tissue (AT) as VLDL (100). Under pathological conditions, de novo FAS by the liver is a primary cause of excessive hepatic steatosis (100). In contrast to glucose, insulin reduces AT lipolysis via suppression of hormonesensitive lipase (HSL), thus regulating the circulation of FFAs in the periphery $(100,101)$. However, obesity-and NAFLDassociated insulin resistance limits HSL suppression, leading to increased AT lipolysis and FFA deposition in the liver (102). FAS is essential for immune cell proliferation in response to inflammatory insult. Macrophages upregulate FAS when undergoing "classical" activation. Monocyte treatment with macrophage colony stimulating factor promotes "classical" activation and expression of sterol regulatory element binding transcription protein 1c (SREBP1c), FAS target genes and increases lipid synthesis (103). Inhibition of SREBP1c reduces macrophage inflammatory capacity (104). Increased FAS drives KC inflammasome activation via nucleotide-binding oligomerization (NOD)-like receptor 3 (NLR3) signaling $(103,105)$. In fact, increased inflammasome activation has been observed in both murine experimental models and human NAFLD (105-107). Inflammasomes, reviewed elsewhere (105), are multiprotein complexes containing nucleotide-binding oligomerization domains NLRs. KCs are a key source of IL$1 \beta$ and caspase 1 , a critical NLR3 component that regulates downstream proinflammatory signaling (e.g., pro-IL-1 $\beta$, proIL-18, ASC), and are elevated in livers from NASH patients $(105,108,109)$. However, given the complexity of inflammasome signaling the underlying mechanism unique to macrophage inflammasome-driven inflammation in NAFLD, these processes warrant further examination. Additional studies are also needed to determine if targeted inhibition of FAS pathways in macrophages is sufficient to reverse inflammasome activation and subsequently improve NAFLD pathology.

\section{Beta-Oxidation}

Beta-oxidation of fatty acids (FA) is central for ensuring cellular and tissue energetic demands by breakdown and conversion of lipids into ATP. Under homeostatic conditions, fat storage and lipolysis are regulated in part by beta-oxidation. Members of the nuclear hormone receptor superfamily known as peroxisome proliferator activated receptors (PPAR $\alpha, \operatorname{PPAR} \beta$, and $\operatorname{PPAR} \gamma)$ are transcriptional modulators of beta-oxidation. $\operatorname{PPAR} \alpha$, which is primarily expressed in the liver, has several endogenous ligands (e.g., FA, eicosanoids and other complex lipids) and acts as a master regulator for FA beta-oxidation $(110,111)$. Given the importance of hepatic steatosis in NAFLD and the relevance of beta-oxidation in immune responses, below we discuss the contribution of both mitochondrial and peroxisomal beta-oxidation to macrophage inflammation. 


\section{Mitochondrial beta-oxidation}

Mitochondrial-beta oxidation breaks down short $\left(<\mathrm{C}_{8}\right)$, medium $\left(\mathrm{C}_{8}-\mathrm{C}_{14}\right)$ and long chain FA $\left(\mathrm{C}_{14}-\mathrm{C}_{20}\right)$ (85). Long chain $\mathrm{FA}$, which are a major component of the standard diet, are shuttled into the mitochondria via carnitine shuttles (carnitine palmitoyltransferase I) by linking with coenzyme A (acyl-CoA) (85, 112). Once acylcarnitine exchanges the carnitine molecule with $\mathrm{CoA}$ via exchange with carnitine palmitoyltransferase II the acyl-CoA proceeds into the betaoxidation cycle. At the inner membrane the enzymatic activity of very long chain acyl-CoA dehydrogenase (VCLAD), shortens long chain acyl-CoAs. Shortened fatty acyl-CoAs are further oxidized by a trifunctional protein complex consisting of: Enoyl-CoA hydratase, 3-hydroxyacyl CoA dehydrogenase, and 3 ketoacyl CoA thiolase. Impaired beta-oxidation in macrophages prevents the degradation of lipids leading to the FA overload and rupture and release of toxic lipid species (85). Although, the traditional view is that FA betaoxidation is essential for polarization of "alternatively" activated macrophages, recent evidence suggest that inhibition of this pathway may in fact promote a "classical" macrophage phenotype. Etomoxir driven inhibition of beta-oxidation or knockdown of CPT-1 results in reduced fatty acid oxidation (FAO) but increased proinflammatory signaling, cytokine production, ER stress and ROS levels (113-115). Thus, additional studies are needed to formally determine how mitochondrial FAO impacts macrophage inflammation and NAFLD progression.

\section{Peroxisomal beta oxidation}

Oxidation of very long chain fatty acids (VLCFAs) $\left(\mathrm{C}>{ }_{21}\right)$ is exclusive to the peroxisome due to the selective presence of very long chain acyl-CoA synthetase (85). Aside from VLCFAs, long chain dicarboxylic acid, eicosanoids, and bile acid precursors are also oxidized within the peroxisomes. Compared to mitochondria, 3 enzymes Acyl-CoA oxidase 1 (Acox1), enoyl CoA hydratase/L-3-hydroxyacyl CoA dehydrogenase bifunctional protein and 3-ketoacyl CoA thiolase regulate peroxisomal beta-oxidation (85). Whole body Acox1 null mice and Acox $1^{\text {Lampe1 }}$ mice, which features a point mutation rendering the Acoxl gene inactive, spontaneously develop steatosis and steatohepatitis $(85,116)$. Acox $1^{\text {Lampe } 1}$ mice also exhibit increased systemic inflammation both at baseline and after LPS challenge in vivo, increased hepatic expression of macrophage recruiting chemokines and macrophage infiltration into the liver following short term high fat diet (HFD) feeding. HFD feeding combined with secondary LPS insult in vivo further exacerbates liver pathologies in Acox $1^{\text {Lampe1 }}$ mice (86). Together, these data suggest that peroxisomal beta-oxidation regulates macrophage-intrinsic inflammation and NAFLD pathogenesis. However, the underlying processes by which peroxisomal beta-oxidation regulates macrophage function and inflammation remain understudied. Similarly, the contribution of peroxisomal beta-oxidation to inflammatory potential of other immune cells and their contribution to NAFLD progression remains poorly understood.

\section{Amino Acid Metabolism}

Amino acids (AA) are critical precursors for several metabolic pathways. For example, glutamine and aspartate are necessary for purine and pyrimidine synthesis as well as feeding the TCA cycle via $\alpha$-ketoglutarate production. Valine and leucine fuel the synthesis of branched chain FA. Direct metabolism of tryptophan (L-TRP) and arginine (L-ARG) by macrophages and other myeloid cells regulate key immunologic processes. For this reason, below we focus on how metabolism of tryptophan and arginine within macrophages modulates their inflammatory potential.

\section{Tryptophan}

In macrophages, L-TRP metabolism is tightly regulated by two isoforms of the enzyme indoleamine 2,3-dioxygenase (IDO1 and IDO2). IDO is the rate limiting enzyme that converts L-TRP into N-formylkynurenine (117). Early reports focused on L-TRP depletion as the central mechanism of immune modulation, yet more recent literature deemphasizes L-TRP depletion and reports kynurenine production as the key regulator of immune responses $(117,118)$. The downstream products of kynurenine modulate immune responses to infection, cancer, and autoimmune diseases $(117,119,120)$. IDO activity is induced in macrophages following IFN $\gamma$, LPS, or TNF stimulation and can be further enhanced with IL-1 $\beta$ co-stimulation (121-125). Several studies have begun to address the contribution of IDOmediated L-TRP metabolism during NAFLD. Kynurenine is increased in the serum of obese subjects, and IDO1 is upregulated in the liver and WAT in obesity (126). IDO-deficient mice displayed elevated liver fibrosis, increased hepatic macrophage infiltration, and higher concentrations of IL-1 $\beta$, IL- 6 , and IFN $\gamma$ in obesity. However, these mice are protected from HFDdriven weight gain, hepatic steatosis, and oxidative stress (127). Interestingly, mice lacking IDO1 expression in macrophages and neutrophils exhibited normal weight gain and insulin sensitivity in obesity (128). Mice with an intact bone-marrow derived immune system, but lacking IDO1 in all other tissues, displayed a similar protection from HFD-induced metabolic disease as the mice with global IDO1 deletion. In sum, these data suggest that IDO contributes to multiple aspects of NAFLD progression and that non-hematopoietic IDO activity may play a key role in regulating NAFLD pathogenesis. Follow-up studies are needed however to dissect the contribution of IDO activity during the full spectrum of NAFLD pathogenesis and to evaluate IDO activity within radiation-resistant tissue macrophages.

L-TRP supplementation has been explored in multiple studies. Mice fed a high fructose diet exhibit reduced liver weight and hepatic lipid accumulation when supplemented with LTRP (129). Clinical studies examining patients with hepatic steatosis or NASH found supplementation, twice daily, with L-TRP for 14 months result in decreased plasma LDL, TG, and gamma gluthamylo transpeptidase levels with a correlative decrease in plasma IL-1 $\beta$, IL-6, and TNF $(130,131)$. Key studies, however, are needed to identify where supplemental L-TRP and its downstream metabolites accumulate, and whether L-TRP is available for IDO activity within the diseased liver. Considering the availability of conditional IDO1 knockout mice (128), it is 
now feasible to separate the contribution of IDO activity by macrophages as well as other immune and non-immune cell types during the initiation and progression of NAFLD. These, studies would help determine how IDO modulates immune responses and NAFLD pathogenesis.

\section{Arginine}

Historically, macrophage polarization was characterized in part by the ability to metabolize L-ARG. "Classically" activated macrophages upregulate inducible nitric oxide synthase (iNOS) which converts L-ARG to L-citrulline and anti-microbial nitric oxide (NO). In contrast, "alternatively" activated macrophages upregulate arginase $1(\operatorname{Arg} 1)$ to metabolize LARG into ornithine and urea $(132,133)$. It is now appreciated that Arg1 and iNOS expression can occur within similarly stimulated macrophages, adding to the complexity of defining "classical" and "alternative" macrophage activation profiles (134-136). Regardless, macrophage L-ARG metabolism has been documented to restrict intrinsic and extrinsic immune cell function. Blocking arginase activity or eliminating Arg1 within macrophages allows for increased L-arginine availability for NO production and anti-microbial activity but can also be associated with unrestricted lymphocyte activity and increased tissue pathology $(132,136-141)$. Thus, understanding how L-ARG metabolism is regulated during altered inflammatory and metabolic states, including NAFLD, is of considerable interest.

Limited studies have focused on the contribution of enzymes involved in the breakdown of L-ARG in NAFLD. Mammals possess two arginase isoforms (Arg1, Arg2) that are differentially expressed within tissues. The importance of macrophage Arg1 in NAFLD has not been addressed. The role of Arg2 in NAFLD, despite published studies, remains undefined. Opposing findings employing Arg2-deficient mice have shown that Arg2-deficiency results in development of spontaneous hepatic steatosis and increased liver injury (142) or promotes decreased NAFLD severity in obesity (143). Although NO contributes to NAFLD, additional studies are needed to determine the critical source of NO as NO inhibitors have various specificities and differ in their ability to regulate disease severity (144). L-ARG supplementation has also been shown to reduce NAFLD severity (145). As such, studies determining the contribution not only of L-ARG utilization, but also of L-ARG synthesis during NAFLD are warranted. The necessity of L-ARG synthesis within macrophages has recently been described during infection, suggesting extracellular L-ARG is not available in sufficient concentrations to drive effective macrophage function $(135,146,147)$. Accounting for the considerable influx of inflammatory macrophages in NAFLD, future studies aimed at addressing macrophage-specific modulation of L-ARG metabolism with existing molecular tools (e.g., $A r g 1^{\text {flox }}, A s l^{\text {flox }}$, Nos2-deficient) (148-150) will be necessary to dissect how various macrophage populations manipulate the liver microenvironment and NAFLD progression.

\section{Macrophages and Trace Metals}

Trace metals including iron, zinc and copper are essential for many cellular functions and for optimal adaptive and innate immune responses (151). Among these three metals, iron and copper exert an important influence on the genesis of NAFLD (152-155). Adults, but not children, with NAFLD manifest increased circulating concentrations of ferritin; however, both age groups exhibit increased transferrin saturation $(153,154)$. Excess iron accrual in the liver, specifically KCs (156) is associated with elevated amounts of hepcidin, which blocks iron egress mediated by ferroportin. Hepcidin binds to ferroportin and enhances its degradation. The accumulation of iron promotes "classically" activated macrophage polarization and production of proinflammatory cytokines that enhance the inflammatory response $(157,158)$. Excessive iron accumulation in both KCs and hepatocytes is associated with NAFLD (152). Inflammatory mediators, induced by lipid overload, drive increased hepcidin and decreased iron export from KCs and hepatocytes, in turn exacerbating NAFLD severity. Although copper is connected to iron homeostasis, the former metal is diminished in patients with NAFLD. Copper deficiency is associated with a decrease in ceruloplasmin ferroxidase which promotes iron release (152, 159). Aside from the effects of copper on iron regulation, the paucity of copper would reduce generation of copper/zinc superoxide dismutases that scavenge ROS and subsequently impairing the cellular defenses to ROS-mediated damage. Despite the knowledge of low zinc concentrations in chronic liver disease and damage (160) the role of zinc in NAFLD has not been investigated. How zinc deficiency augments liver damage is not well defined. Experiments determining the necessity of superoxide dismutases to combat excess ROS would provide valuable insight but have yet to be performed.

\section{Adipose Tissue/Adipocytes and NAFLD}

The traditional perspective of AT was that of a simplistic fat storing/releasing organ playing a role in energy homeostasis (161). It is now well-appreciated that AT is a highly metabolic, active and plastic organ comprised of various types of cells (e.g., adipocytes, progenitor stem cells within the stromal vascular fraction, endothelial cells, fibroblasts, and immune cells) $(162,163)$. The AT regulates the accommodation of excess energy through storage of circulating dietary lipids and de novo lipogenesis. In the case of nutrient shortage, lipolysis controls/regulates the release of hydrolyzed TGs as glycerol and FFAs to provide energy to surrounding tissues (164-166). Obesityassociated changes in AT robustly modify AT function including production of hormones, cytokines and adipokines. Which cells within AT tissue contribute to such changes and how the low-grade systemic and AT inflammatory state in obesity/metabolic disease impacts AT function is poorly understood.

Adipose tissue macrophages (ATMs) are believed to play a major role in regulating AT inflammation. In general, healthy AT, is believed to contain a balance between "alternatively" and "classically" activated ATMs. In contrast, the unhealthy/inflammatory AT, houses an increased number of "classically" activated ATMs. "Classically" activated ATMs produce an array of proinflammatory mediators (e.g., IL-6, TNF, IL-1 $\beta$, IFN $\gamma$ ) that further amplify AT inflammation and promote 
additional macrophage and other immune cell recruitment and activation. Cumulatively, such events, in obesity, fuel a chronic low-grade inflammation within the AT $(167,168)$. In addition to the enhanced release of soluble mediators, AT inflammation drives expression of integrin $\alpha 4$ on macrophages and vascular cell adhesion molecule 1 (VCAM-1) on adipocytes allowing for AT macrophage accrual (43). The inhibition of integrin $\alpha 4$ reduces ATM retention and AT inflammation. Notably, individuals with NAFLD exhibit high expression of VCAM-1 in AT underlining the importance of this cell-cell interaction pathways (169).

Adipocytes play a pivotal role in metabolic disease by promoting chronic inflammation via release of FFAs in response to increased circulating levels of TNF. These FFAs translocate to the liver and skeletal muscle propagating inflammation and insulin resistance $(170,171)$. Mechanistically, TNF inhibits $\operatorname{PPAR} \gamma(172)$ and CCAAT/enhancer binding protein $(\mathrm{C} / \mathrm{EBP} \alpha)$ in adipocytes that is needed for the expression of adipocyte-specific GLUT4 and insulin receptor (IR) to maintain insulin sensitivity
$(173,174)$. This suggests that like ATMs, adipocytes themselves play an important role in maintaining AT metabolic processes. Recent studies demonstrate that adipocytes, like immune cells, exhibit immune-like potential $(175,176)$. Specifically, adipocytes express various innate immune receptors including RIG-Ilike receptors (RLR), NLRs, and nucleotide oligomerization domains (NODs) (177, 178). NOD-1 signaling suppresses adipocyte differentiation and contributes to induction of the NF-kB (177, 179). Adipocyte sensing of various PAMPs leads to production of multiple inflammatory mediators (e.g., cytokines, chemokines, adipokines) (180). In obesity, the main mechanisms associated with unlocking adipocyte-intrinsic inflammation are: (a) obesity-associated endotoxemia and (b) AT hypoxic micro-environment which leads to ER stress, inflammatory cytokine production, cell death, release of lipid content and debris and induction of the inflammatory mediators (181). Adipocyte production of inflammatory mediators is potentially sensed by ATMs and leads to their activation $(161,168,180,182)$. Adiponectin, an adipokine, exerts either

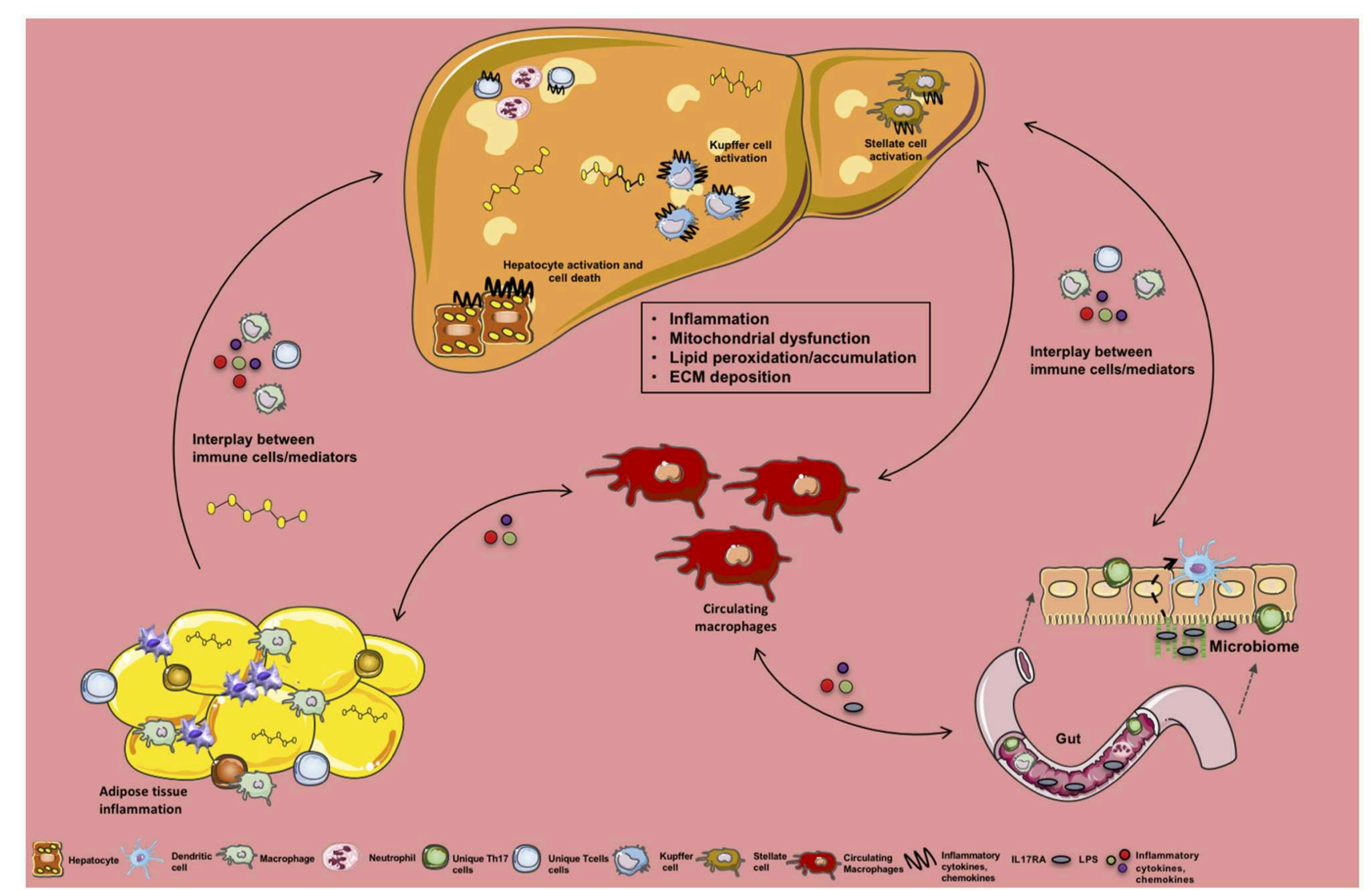

FIGURE 3 | Crosstalk between tissue-specific inflammation and macrophage function in NAFLD. Schematic overview of the crosstalk between various organs, their specific immune cells and inflammatory mediators during NAFLD. Obesity-associated low-grade, chronic inflammation and altered gut microbiome impacts immune cell crosstalk between the gut, circulating monocytes/macrophages, and the liver. In addition, obesity-associated adipocyte expansion promotes hypoxia leading to adipose tissue (AT) inflammation, activation of adipose tissue macropahes (ATMs) and fuels infiltration of various immune cells and inflammatory mediator production (e.g., FFAs, ROS, cytokines, chemokines) to be sensed by circulating macrophages and hepatocytes. Collectively these processes alter hepatocellular lipid metabolism, contributing to steatosis and proinflammatory cytokine (IL-17, TNF, IFN $\gamma$, IL-6) and chemokine production (CCL2, CXCL9, CXCL10). Moreover, this inflammatory state activates hepatic stellate cells (HSCs) and Kupffer cells (KCs) in turn contributing to extracellular matrix deposition (collagen fibers) and progression to fibrosis. 
anti- or pro-inflammatory effects on macrophages. It inhibits macrophage functions (e.g., phagocytosis, cytokine production) and induces proliferation of "alternatively" activated macrophage in AT (183-185). Conversely, adiponectin also induces proinflammatory signaling cascades through NF-kB activation and upregulation of pro-inflammatory cytokines (e.g., TNF- $\alpha$, IL6 , and IL-8) $(186,187)$. However, detailed analysis of specific adipocyte mediators and adipokines relevant to altered ATMs polarization and activation is needed. Similarly, whether obesityactivated adipocytes or ATMs directly play a role in NAFLD pathogenesis is not fully understood and should be further investigated. A brief summary of the above discussed processes is depicted in Figure 3.

\section{Therapies}

Ultimately, the improvement of experimental models to more closely recapitulate human NAFLD would be ideal for the discovery and development of therapies targeting various metabolic pathways in macrophages. Diet and lifestyle changes help in reversing NAFLD progression. Thus, it is not surprising that several pharmacological drugs that target metabolic and inflammatory and molecular mechanisms important in NAFLD progression are currently being examined (188). Hepatic lipid accumulation is an initial driver of NAFLD pathogenesis (9, 84). Intuitively, use of therapeutic drugs that target lipid metabolism is actively pursued. Glitazones, which are a class of insulin-sensitizing drugs, are effective in regulating lipid metabolism. They increase FAS and FA uptake by adipocytes, thus increasing lipid loading in AT instead of ectopic organs (e.g., liver and muscle) (189, 190). However, due to their association with increased risks of heart failure the use of glitazones as a treatment option has not been pursued in the clinic (191, 192). Sodium glucose co-transporter 2 (SGLT2) inhibitors have also proven efficacious in regulating NAFLD-associated dyslipidemia by inhibiting hepatic expression of lipogenic genes (e.g., sterol regulatory-element binding protein 1-c, fatty acid synthase, acetyl-CoA carboxylase 1, and sterol CoA desaturase), hepatic macrophage infiltration and expression of inflammatory cytokine production (190, 193, 194). However, underlying mechanisms that govern this process remains an area of investigation. Upregulation of oxidative stress, inflammation and apoptosis pathways are associated with NAFLD pathogenesis. NASH patients display increased hepatic activation of apoptosis signal-regulating kinase 1 (Ask1). Activation of Ask1 by TNF causes oxidative and ER stress, and induction of p38 and JNK signaling $(188,190,195)$. Ask1 inhibition reduced hepatic steatosis, inflammation and fibrosis $(196,197)$. However, given that phenotypical outcomes of Ask1 inhibition in mice are not often recapitulated in humans, more effective "humanized" mouse models are needed (198, 199). Further, the effects of Ask1 inhibition on macrophage inflammation in NAFLD pathogenesis remains underdefined. Limiting the detrimental effects of obesity-associated microbiome alteration and subsequent systemic endotoxemia which contribute to NAFLD pathogenesis is another active area of investigation for drug development. Excessive PRR activation and inflammation resulting in liver injury is characteristic of NAFLD. JKB-121, a TLR4 antagonist, prevents LPS induced inflammatory liver injury in MCD diet models of NAFLD. However, given that obesity modulates the expression of multiple TLRs, more studies are needed to determine the impact of ablation of other TLRs in NAFLD pathogenesis. In addition, there are several other therapeutic approaches regarding use of ACC inhibitors, fructose inhibitors and obetocholic acid inhibitors $(188,190)$ for the treatment of NAFLD. In sum, several potential avenues for NAFLD therapies are being pursued. Specifically, there is a need for studies to allow for HFD-driven induction of hepatic fibrosis (41), eliminate gender bias by employing a more "human"-like disease state (e.g., thermoneutrality) (200), CCL4 experimental models of fibrosis (201) use of various murine strains/genotypes to mimic genetic diversity as well as expansion of such findings into non-human primate models of NAFLD (198). Use of such wide ranging experimental models would be beneficial in the development of therapeutic targets that may prove more effective in the clinic. Thus, in sum, given the interplay between metabolism and inflammation, additional therapies targeting macrophage polarization, chemo-attracting, inflammatory and metabolic pathways are needed-something that may be achieved by improving experimental modeling of disease.

\section{CONCLUSION}

Overall, this review highlights the inflammatory processes associated with macrophage polarization, tissue recruitment and inflammation and the role of such processes in NAFLD. We also extensively discuss how cellular metabolic pathways may contribute to macrophage-driven inflammation. Given the metabolic changes in obesity and inflammation the potential benefits to be gained from understanding the interplay between various metabolic and inflammatory pathways in macrophages are immense. Further elucidation of the crosstalk between macrophages and other tissues/immune cells similarly remains an exciting area of exploration. However, subsequent to the detailed interrogation of the afore discussed cellular and molecular processes in NAFLD, validation of such processes in multiple experimental models of NAFLD will be required.

\section{AUTHOR CONTRIBUTIONS}

JO, MM, MM-F, MD, GD, JQ, and SD wrote the manuscript. All authors have reviewed the manuscript and approve the final version.

\section{FUNDING}

This work was supported in part by NIH R01DK099222 and American Diabetes Association (ADA) 1-18-IBS-100 (to SD); CCHMC Pediatric Diabetes and Obesity Center (to SD); R01DK099222-02S1 (associated with SD and MM-F); American Heart Association (AHA) 17POST33650045 and ADA 1-19-PMF-019 (to MM-F); University of Cincinnati Provost 
Graduate Fellowship (to JO) and PHS Grant P30 DK078392 Pathology of the Digestive Disease Research Core Center at CCHMC (associated with SD), NIH R01AI116668 (to JQ), and NIH T32AI118697 (MM appointee).

\section{REFERENCES}

1. Perumpail BJ, Khan MA, Yoo ER, Cholankeril G, Kim D, Ahmed A. Clinical epidemiology and disease burden of nonalcoholic fatty liver disease. World $J$ Gastroenterol. (2017) 23:8263-76. doi: 10.3748/wjg.v23.i47.8263

2. Fabbrini E, Sullivan S, Klein S. Obesity and nonalcoholic fatty liver disease: biochemical, metabolic, and clinical implications. Hepatology. (2010) 51:679-89. doi: 10.1002/hep.23280

3. Younossi ZM, Blissett D, Blissett R, Henry L, Stepanova M, Younossi $\mathrm{Y}$, et al. The economic and clinical burden of nonalcoholic fatty liver disease in the United States and Europe. Hepatology. (2016) 64:1577-86. doi: $10.1002 /$ hep. 28785

4. Hardy T, Oakley F, Anstee QM, Day CP. Nonalcoholic Fatty Liver Disease: Pathogenesis and Disease Spectrum. Annu Rev Pathol. (2016) 11:451-96. doi: 10.1146/annurev-pathol-012615-044224

5. Arrese M, Cabrera D, Kalergis AM, Feldstein AE. Innate immunity and inflammation in NAFLD/NASH. Dig Dis Sci. (2016) 61:1294-303. doi: $10.1007 / \mathrm{s} 10620-016-4049-\mathrm{x}$

6. Cha JY, Kim DH, Chun KH. The role of hepatic macrophages in nonalcoholic fatty liver disease and nonalcoholic steatohepatitis. Lab Anim Res. (2018) 34:133-9. doi: 10.5625/lar.2018.34.4.133

7. Kwon $\mathrm{H}$, Pessin JE. Adipokines mediate inflammation and insulin resistance. Front Endocrinol. (2013) 4:71. doi: 10.3389/fendo.2013.00071

8. Huang J, Viswakarma N, Yu S, Jia Y, Bai L, Vluggens A, et al. Progressive endoplasmic reticulum stress contributes to hepatocarcinogenesis in fatty acyl-CoA oxidase 1-deficient mice. Am J Pathol. (2011) 179:703-13. doi: 10.1016/j.ajpath.2011.04.030

9. Cobbina E, Akhlaghi F. Non-alcoholic fatty liver disease (NAFLD) - pathogenesis, classification, and effect on drug metabolizing enzymes and transporters. Drug Metab Rev. (2017) 49:197-211. doi: 10.1080/03602532.2017.1293683

10. Giles DA, Moreno-Fernandez ME, Stankiewicz TE, Cappelletti M, Huppert SS, Iwakura Y, et al. Regulation of Inflammation by IL17A and IL-17F Modulates Non-Alcoholic Fatty Liver Disease Pathogenesis. PLoS ONE. (2016) 11:e0149783. doi: 10.1371/journal.pone.0 149783

11. Rosso C, Kazankov K, Younes R, Esmaili S, Marietti M, Sacco M, et al. Crosstalk between adipose tissue insulin resistance and liver macrophages in non-alcoholic fatty liver disease. J Hepatol. (2019) 71:101221. doi: 10.1016/j.jhep.2019.06.031

12. Cani PD, Amar J, Iglesias MA, Poggi M, Knauf C, Bastelica D, et al. Metabolic endotoxemia initiates obesity and insulin resistance. Diabetes. (2007) 56:1761-72. doi: 10.2337/db06-1491

13. Grunhut J, Wang W, Aykut B, Gakhal I, Torres-Hernandez A, Miller G. Macrophages in nonalcoholic steatohepatitis: friend or foe? Eur Med J Hepatol. (2018) 6:100-9.

14. Wree A, Broderick L, Canbay A, Hoffman HM, Feldstein AE. From NAFLD to NASH to cirrhosis-new insights into disease mechanisms. Nat Rev Gastroenterol Hepatol. (2013) 10:627-36. doi: 10.1038/nrgastro.2013.149

15. Miura K, Ohnishi H. Role of gut microbiota and Toll-like receptors in nonalcoholic fatty liver disease. World J Gastroenterol. (2014) 20:7381-91. doi: 10.3748/wjg.v20.i23.7381

16. Phan AT, Goldrath AW, Glass CK. Metabolic and epigenetic coordination of $\mathrm{T}$ cell and macrophage immunity. Immunity. (2017) 46:714-29. doi: 10.1016/j.immuni.2017.04.016

17. Braunersreuther V, Viviani GL, Mach F, Montecucco F. Role of cytokines and chemokines in non-alcoholic fatty liver disease. World J Gastroenterol. (2012) 18:727-35. doi: 10.3748/wjg.v18.i8.727

\section{ACKNOWLEDGMENTS}

We thank Jessica R. Doll for the careful review of the manuscript. Figures were generated in part using https://smart.servier.com/.

18. Giles DA, Moreno-Fernandez ME, Divanovic S. IL-17 Axis driven inflammation in non-alcoholic fatty liver disease progression. Curr Drug Targets. (2015) 16:1315-23. doi: 10.2174/1389450116666150531153627

19. Karlmark KR, Weiskirchen R, Zimmermann HW, Gassler N, Ginhoux F, Weber C, et al. Hepatic recruitment of the inflammatory Gr1+ monocyte subset upon liver injury promotes hepatic fibrosis. Hepatology. (2009) 50:261-74. doi: 10.1002/hep. 22950

20. Wasmuth HE, Tacke F, Trautwein C. Chemokines in liver inflammation and fibrosis. Semin Liver Dis. (2010) 30:215-25. doi: 10.1055/s-0030-1255351

21. Obstfeld AE, Sugaru E, Thearle M, Francisco AM, Gayet C, Ginsberg HN, et al. $\mathrm{C}$-C chemokine receptor 2 (CCR2) regulates the hepatic recruitment of myeloid cells that promote obesity-induced hepatic steatosis. Diabetes. (2010) 59:916-25. doi: 10.2337/db09-1403

22. Holt AP, Haughton EL, Lalor PF, Filer A, Buckley CD, Adams DH. Liver myofibroblasts regulate infiltration and positioning of lymphocytes in human liver. Gastroenterology. (2009) 136:705-14. doi: 10.1053/j.gastro.2008.10.020

23. Kazankov K, Jorgensen SMD, Thomsen KL, Moller HJ, Vilstrup H, George $\mathrm{J}$, et al. The role of macrophages in nonalcoholic fatty liver disease and nonalcoholic steatohepatitis. Nat Rev Gastroenterol Hepatol. (2019) 16:14559. doi: 10.1038/s41575-018-0082-x

24. Mak A, Uetrecht J. Involvement of CCL2/CCR2 macrophage recruitment in amodiaquine-induced liver injury. J Immunotoxicol. (2019) 2019:1-6. doi: 10.1080/1547691X.2018.1516014

25. Kanda H, Tateya S, Tamori Y, Kotani K, Hiasa K, Kitazawa R, et al. MCP-1 contributes to macrophage infiltration into adipose tissue, insulin resistance, and hepatic steatosis in obesity. J Clin Invest. (2006) 116:1494505. doi: 10.1172/JCI26498

26. Weisberg SP, Hunter D, Huber R, Lemieux J, Slaymaker S, Vaddi K, et al. CCR2 modulates inflammatory and metabolic effects of high-fat feeding. $J$ Clin Invest. (2006) 116:115-24. doi: 10.1172/JCI24335

27. Tamura Y, Sugimoto M, Murayama T, Minami M, Nishikaze Y, Ariyasu $\mathrm{H}$, et al. C-C chemokine receptor 2 inhibitor improves diet-induced development of insulin resistance and hepatic steatosis in mice. J Atheroscler Thromb. (2010) 17:219-28. doi: 10.5551/jat.3368

28. Seki E, De Minicis S, Gwak GY, Kluwe J, Inokuchi S, Bursill CA, et al. CCR1 and CCR5 promote hepatic fibrosis in mice. J Clin Invest. (2009) 119:1858-70. doi: 10.1172/JCI37444

29. Berres ML, Koenen RR, Rueland A, Zaldivar MM, Heinrichs D, Sahin H, et al. Antagonism of the chemokine Ccl5 ameliorates experimental liver fibrosis in mice. J Clin Invest. (2010) 120:4129-40. doi: 10.1172/JCI41732

30. Miura K, Yang L, van Rooijen N, Ohnishi H, Seki E. Hepatic recruitment of macrophages promotes nonalcoholic steatohepatitis through CCR2. Am J Physiol Gastrointest Liver Physiol. (2012) 302:G1310-21. doi: 10.1152/ajpgi.00365.2011

31. Heymann F, Hammerich L, Storch D, Bartneck M, Huss S, Russeler V, et al. Hepatic macrophage migration and differentiation critical for liver fibrosis is mediated by the chemokine receptor $\mathrm{C}-\mathrm{C}$ motif chemokine receptor 8 in mice. Hepatology. (2012) 55:898-909. doi: 10.1002/hep.24764

32. Baeck C, Wei X, Bartneck M, Fech V, Heymann F, Gassler N, et al. Pharmacological inhibition of the chemokine $\mathrm{C}-\mathrm{C}$ motif chemokine ligand 2 (monocyte chemoattractant protein 1) accelerates liver fibrosis regression by suppressing Ly-6C(+) macrophage infiltration in mice. Hepatology. (2014) 59:1060-72. doi: 10.1002/hep.26783

33. Zhang X, Han J, Man K, Li X, Du J, Chu ES, et al. CXC chemokine receptor 3 promotes steatohepatitis in mice through mediating inflammatory cytokines, macrophages and autophagy. J Hepatol. (2016) 64:160-70. doi: 10.1016/j.jhep.2015.09.005 
34. Tomita K, Freeman BL, Bronk SF, LeBrasseur NK, White TA, Hirsova P, et al. CXCL10-Mediates Macrophage, but not Other Innate Immune CellsAssociated Inflammation in Murine Nonalcoholic Steatohepatitis. Sci Rep. (2016) 6:28786. doi: 10.1038/srep28786

35. Friedman SL, Ratziu V, Harrison SA, Abdelmalek MF, Aithal GP, Caballeria $\mathrm{J}$, et al. A randomized, placebo-controlled trial of cenicriviroc for treatment of nonalcoholic steatohepatitis with fibrosis. Hepatology. (2018) 67:1754-67. doi: 10.1002/hep. 29477

36. Harley IT, Stankiewicz TE, Giles DA, Softic S, Flick LM, Cappelletti M, et al. IL-17 signaling accelerates the progression of nonalcoholic fatty liver disease in mice. Hepatology. (2014) 59:1830-9. doi: 10.1002/hep.26746

37. Gomes AL, Teijeiro A, Buren S, Tummala KS, Yilmaz M, Waisman A, et al. Metabolic inflammation-associated IL-17A causes non-alcoholic steatohepatitis and hepatocellular carcinoma. Cancer Cell. (2016) 30:161-75. doi: 10.1016/j.ccell.2016.05.020

38. Baffy G. Kupffer cells in non-alcoholic fatty liver disease: the emerging view. J Hepatol. (2009) 51:212-23. doi: 10.1016/j.jhep.2009.03.008

39. Robinson MW, Harmon C, O'Farrelly C. Liver immunology and its role in inflammation and homeostasis. Cell Mol Immunol. (2016) 13:267-76. doi: $10.1038 / \mathrm{cmi} .2016 .3$

40. Takeuchi O, Akira S. Pattern recognition receptors and inflammation. Cell. (2010) 140:805-20. doi: 10.1016/j.cell.2010.01.022

41. Kohli R, Kirby M, Xanthakos SA, Softic S, Feldstein AE, Saxena V, et al. High-fructose, medium chain trans fat diet induces liver fibrosis and elevates plasma coenzyme Q9 in a novel murine model of obesity and nonalcoholic steatohepatitis. Hepatology. (2010) 52:934-44. doi: 10.1002/hep.23797

42. Mayoral Monibas R, Johnson AM, Osborn O, Traves PG, Mahata SK. Distinct hepatic macrophage populations in lean and obese mice. Front Endocrinol (Lausanne). (2016) 7:152. doi: 10.3389/fendo.2016.00152

43. Kim SY, Jeong JM, Kim SJ, Seo W, Kim MH, Choi WM, et al. Proinflammatory hepatic macrophages generate ROS through NADPH oxidase 2 via endocytosis of monomeric TLR4-MD2 complex. Nat Commun. (2017) 8:2247. doi: 10.1038/s41467-017-02325-2

44. Classen A, Lloberas J, Celada A. Macrophage activation: classical versus alternative. Methods Mol Biol. (2009) 531:29-43. doi: 10.1007/978-1-59745-396-7_3

45. Kang K, Reilly SM, Karabacak V, Gangl MR, Fitzgerald K, Hatano B, et al. Adipocyte-derived Th2 cytokines and myeloid PPARdelta regulate macrophage polarization and insulin sensitivity. Cell Metab. (2008) 7:48595. doi: 10.1016/j.cmet.2008.04.002

46. Gordon S. Alternative activation of macrophages. Nat Rev Immunol. (2003) 3:23-35. doi: 10.1038/nri978

47. Saberi M, Woods NB, de Luca C, Schenk S, Lu JC, Bandyopadhyay G, et al. Hematopoietic cell-specific deletion of toll-like receptor 4 ameliorates hepatic and adipose tissue insulin resistance in high-fat-fed mice. Cell Metab. (2009) 10:419-29. doi: 10.1016/j.cmet.2009.09.006

48. Solinas G, Vilcu C, Neels JG, Bandyopadhyay GK, Luo JL, Naugler W, et al. JNK1 in hematopoietically derived cells contributes to diet-induced inflammation and insulin resistance without affecting obesity. Cell Metab. (2007) 6:386-97. doi: 10.1016/j.cmet.2007.09.011

49. Arkan MC, Hevener AL, Greten FR, Maeda S, Li ZW, Long JM, et al. IKK-beta links inflammation to obesity-induced insulin resistance. Nat Med. (2005) 11:191-8. doi: 10.1038/nm1185

50. Cai D, Yuan M, Frantz DF, Melendez PA, Hansen L, Lee J, et al. Local and systemic insulin resistance resulting from hepatic activation of IKK-beta and NF-kappaB. Nat Med. (2005) 11:183-90. doi: 10.1038/nm1166

51. Mas E, Danjoux M, Garcia V, Carpentier S, Segui B, Levade T. IL-6 deficiency attenuates murine diet-induced non-alcoholic steatohepatitis. PLoS ONE. (2009) 4:e7929. doi: 10.1371/journal.pone.0007929

52. Papanicolaou DA, Wilder RL, Manolagas SC, Chrousos GP. The pathophysiologic roles of interleukin-6 in human disease. Ann Intern Med. (1998) 128:127-37. doi: 10.7326/0003-4819-128-2-19980115000009

53. Ray A, Tatter SB, Santhanam U, Helfgott DC, May LT, Sehgal PB. Regulation of expression of interleukin-6. Molecular and clinical studies. Ann N Y Acad Sci. (1989) 557:353-61; discussion 61-2. doi: 10.1111/j.1749-6632.1989.tb24028.x
54. Brass EP, Vetter WH. Interleukin-6, but not tumour necrosis factor-alpha, increases lipogenesis in rat hepatocyte primary cultures. Biochem J. (1994) 301 (Pt 1):193-7. doi: 10.1042/bj3010193

55. Fernandez-Real JM, Lopez-Bermejo A, Ricart W. Cross-talk between iron metabolism and diabetes. Diabetes. (2002) 51:2348-54. doi: 10.2337/diabetes.51.8.2348

56. Wellen KE, Hotamisligil GS. Obesity-induced inflammatory changes in adipose tissue. J Clin Invest. (2003) 112:1785-8. doi: 10.1172/JCI20514

57. Senn JJ, Klover PJ, Nowak IA, Mooney RA. Interleukin-6 induces cellular insulin resistance in hepatocytes. Diabetes. (2002) 51:3391-9. doi: 10.2337/diabetes.51.12.3391

58. Bastard JP, Maachi M, Lagathu C, Kim MJ, Caron M, Vidal H, et al. Recent advances in the relationship between obesity, inflammation, and insulin resistance. Eur Cytokine Netw. (2006) 17:4-12.

59. Kugelmas M, Hill DB, Vivian B, Marsano L, McClain CJ. Cytokines and NASH: a pilot study of the effects of lifestyle modification and vitamin $\mathrm{E}$. Hepatology. (2003) 38:413-9. doi: 10.1053/jhep.2003.50316

60. Haukeland JW, Damas JK, Konopski Z, Loberg EM, Haaland T, Goverud $\mathrm{I}$, et al. Systemic inflammation in nonalcoholic fatty liver disease is characterized by elevated levels of CCL2. J Hepatol. (2006) 44:1167-74. doi: 10.1016/j.jhep.2006.02.011

61. Wieckowska A, Feldstein AE. Diagnosis of nonalcoholic fatty liver disease: invasive versus noninvasive. Semin Liver Dis. (2008) 28:386-95. doi: 10.1055/s-0028-1091983

62. Yamaguchi K, Itoh Y, Yokomizo C, Nishimura T, Niimi T, Fujii H, et al. Blockade of interleukin-6 signaling enhances hepatic steatosis but improves liver injury in methionine choline-deficient diet-fed mice. Lab Invest. (2010) 90:1169-78. doi: 10.1038/labinvest.2010.75

63. Harris HW, Grunfeld C, Feingold KR, Rapp JH. Human very low density lipoproteins and chylomicrons can protect against endotoxin-induced death in mice. J Clin Invest. (1990) 86:696-702. doi: 10.1172/JCI114765

64. Grunfeld C, Pang M, Doerrler W, Shigenaga JK, Jensen P, Feingold KR. Lipids, lipoproteins, triglyceride clearance, and cytokines in human immunodeficiency virus infection and the acquired immunodeficiency syndrome. J Clin Endocrinol Metab. (1992) 74:1045-52. doi: $10.1210 /$ jcem.74.5.1373735

65. Borst SE. The role of TNF-alpha in insulin resistance. Endocrine. (2004) 23(2-3):177-82. doi: 10.1385/ENDO:23:2-3:177

66. Fon Tacer K, Kuzman D, Seliskar M, Pompon D, Rozman D. TNF-alpha interferes with lipid homeostasis and activates acute and proatherogenic processes. Physiol Genomics. (2007) 31:216-27. doi: 10.1152/physiolgenomics.00264.2006

67. Wullaert A, van Loo G, Heyninck K, Beyaert R. Hepatic tumor necrosis factor signaling and nuclear factor-kappaB: effects on liver homeostasis and beyond. Endocr Rev. (2007) 28:365-86. doi: 10.1210/er.2006-0031

68. Tomita K, Tamiya G, Ando S, Ohsumi K, Chiyo T, Mizutani A, et al. Tumour necrosis factor alpha signalling through activation of Kupffer cells plays an essential role in liver fibrosis of non-alcoholic steatohepatitis in mice. Gut. (2006) 55:415-24. doi: 10.1136/gut.2005.071118

69. Kakino S, Ohki T, Nakayama H, Yuan X, Otabe S, Hashinaga T, et al. Pivotal role of TNF-alpha in the development and progression of nonalcoholic fatty liver disease in a murine model. Horm Metab Res. (2018) 50:80-7. doi: 10.1055/s-0043-118666

70. Tan Q, Hu J, Yu X, Guan W, Lu H, Yu Y, et al. The role of IL-1 family members and kupffer cells in liver regeneration. Biomed Res Int. (2016) 2016:6495793. doi: 10.1155/2016/6495793

71. Negrin KA, Roth Flach RJ, DiStefano MT, Matevossian A, Friedline RH, Jung D, et al. IL-1 signaling in obesity-induced hepatic lipogenesis and steatosis. PLoS ONE. (2014) 9:e107265. doi: 10.1371/journal.pone.0107265

72. Garlanda C, Dinarello CA, Mantovani A. The interleukin-1 family: back to the future. Immunity. (2013) 39:1003-18. doi: 10.1016/j.immuni.2013.11.010

73. Meier RPH, Meyer J, Montanari E, Lacotte S, Balaphas A, Muller YD, et al. Interleukin-1 receptor antagonist modulates liver inflammation and fibrosis in mice in a model-dependent manner. Int J Mol Sci. (2019) 20:E1295. doi: 10.3390/ijms20061295

74. Gehrke N, Hovelmeyer N, Waisman A, Straub BK, Weinmann-Menke J, Worns MA, et al. Hepatocyte-specific deletion of IL1-RI attenuates liver 
injury by blocking IL-1 driven autoinflammation. J Hepatol. (2018) 68:98695. doi: 10.1016/j.jhep.2018.01.008

75. Janssens S, Beyaert R. A universal role for MyD88 in TLR/IL1R-mediated signaling. Trends Biochem Sci. (2002) 27:474-82. doi: 10.1016/S0968-0004(02)02145-X

76. Larsen CM, Faulenbach M, Vaag A, Volund A, Ehses JA, Seifert B, et al. Interleukin-1-receptor antagonist in type 2 diabetes mellitus. $\mathrm{N} \mathrm{Engl} \mathrm{J} \mathrm{Med.}$ (2007) 356:1517-26. doi: 10.1056/NEJMoa065213

77. Gomez R, Villalvilla A, Largo R, Gualillo O, Herrero-Beaumont G. TLR4 signalling in osteoarthritis-finding targets for candidate DMOADs. Nat Rev Rheumatol. (2015) 11:159-70. doi: 10.1038/nrrheum.2014.209

78. Day CP, James OF. Steatohepatitis: a tale of two "hits"? Gastroenterology. (1998) 114:842-5. doi: 10.1016/S0016-5085(98)70599-2

79. Crosas-Molist E, Fabregat I. Role of NADPH oxidases in the redox biology of liver fibrosis. Redox Biol. (2015) 6:106-11. doi: 10.1016/j.redox.2015.07.005

80. Mukherjee R, Moreno-Fernandez ME, Giles DA, Cappelletti M, Stankiewicz TE, Chan CC, et al. Nicotinamide adenine dinucleotide phosphate (reduced) oxidase 2 modulates inflammatory vigor during nonalcoholic fatty liver disease progression in mice. Hepatol Commun. (2018) 2:546-60. doi: 10.1002/hep4.1162

81. Chapman NM, Shrestha S, Chi H. Metabolism in immune cell differentiation and function. Adv Exp Med Biol. (2017) 1011:1-85. doi: 10.1007/978-94-024-1170-6_1

82. Krzywinska E, Stockmann C. Hypoxia, metabolism and immune cell function. Biomedicines. (2018) 6:E56. doi: 10.3390/biomedicines6020056

83. Cirulli ET, Guo L, Leon Swisher C, Shah N, Huang L, Napier LA, et al. Profound perturbation of the metabolome in obesity is associated with health risk. Cell Metab. (2019) 29:488-500 e2. doi: 10.1016/j.cmet.2018. 09.022

84. Reddy JK, Rao MS. Lipid metabolism and liver inflammation. II. Fatty liver disease and fatty acid oxidation. Am J Physiol Gastrointest Liver Physiol. (2006) 290:G852-8. doi: 10.1152/ajpgi.00521.2005

85. Reddy JK, Hashimoto T. Peroxisomal beta-oxidation and peroxisome proliferator-activated receptor alpha: an adaptive metabolic system. Annu Rev Nutr. (2001) 21:193-230. doi: 10.1146/annurev.nutr.21.1.193

86. Moreno-Fernandez ME, Giles DA, Stankiewicz TE, Sheridan R, Karns $\mathrm{R}$, Cappelletti $\mathrm{M}$, et al. Peroxisomal beta-oxidation regulates whole body metabolism, inflammatory vigor, and pathogenesis of nonalcoholic fatty liver disease. JCI Insight. (2018) 3:93626. doi: 10.1172/jci.insight. 93626

87. Olefsky JM, Glass CK. Macrophages, inflammation, and insulin resistance. Annu Rev Physiol. (2010) 72:219-46. doi: 10.1146/annurev-physiol-021909-135846

88. Diskin C, Palsson-McDermott EM. Metabolic modulation in macrophage effector function. Front Immunol. (2018) 9:270. doi: $10.3389 /$ fimmu.2018.00270

89. Wang X, de Carvalho Ribeiro M, Iracheta-Vellve A, Lowe P, Ambade A, Satishchandran A, et al. Macrophage-specific hypoxia-inducible factor-1alpha contributes to impaired autophagic flux in nonalcoholic steatohepatitis. Hepatology. (2019) 69:545-63. doi: 10.1002/hep. 30215

90. Tannahill GM, Curtis AM, Adamik J, Palsson-McDermott EM, McGettrick AF, Goel G, et al. Succinate is an inflammatory signal that induces IL1beta through HIF-1alpha. Nature. (2013) 496:238-42. doi: 10.1038/nature 11986

91. Jha AK, Huang SC, Sergushichev A, Lampropoulou V, Ivanova Y, Loginicheva E, et al. Network integration of parallel metabolic and transcriptional data reveals metabolic modules that regulate macrophage polarization. Immunity. (2015) 42:419-30. doi: 10.1016/j.immuni.2015.02.005

92. Haschemi A, Kosma P, Gille L, Evans CR, Burant CF, Starkl P, et al. The sedoheptulose kinase CARKL directs macrophage polarization through control of glucose metabolism. Cell Metab. (2012) 15:813-26. doi: 10.1016/j.cmet.2012.04.023

93. Koo SJ, Szczesny B, Wan X, Putluri N, Garg NJ. Pentose phosphate shunt modulates reactive oxygen species and nitric oxide production controlling trypanosoma cruzi in macrophages. Front Immunol. (2018) 9:202. doi: $10.3389 /$ fimmu.2018.00202
94. Pollak N, Dolle C, Ziegler M. The power to reduce: pyridine nucleotidessmall molecules with a multitude of functions. Biochem J. (2007) 402:205-18. doi: $10.1042 / B J 20061638$

95. Ray PD, Huang BW, Tsuji Y. Reactive oxygen species (ROS) homeostasis and redox regulation in cellular signaling. Cell Signal. (2012) 24:981-90. doi: 10.1016/j.cellsig.2012.01.008

96. Baardman J, Verberk SGS, Prange KHM, van Weeghel M, van der Velden $\mathrm{S}$, Ryan DG, et al. A Defective pentose phosphate pathway reduces inflammatory macrophage responses during hypercholesterolemia. Cell Rep. (2018) 25:2044-52 e5. doi: 10.1016/j.celrep.2018.10.092

97. Koh HJ, Lee SM, Son BG, Lee SH, Ryoo ZY, Chang KT, et al. Cytosolic NADP+-dependent isocitrate dehydrogenase plays a key role in lipid metabolism. J Biol Chem. (2004) 279:39968-74. doi: $10.1074 /$ jbc.M402260200

98. Al-Dwairi A, Pabona JM, Simmen RC, Simmen FA. Cytosolic malic enzyme 1 (ME1) mediates high fat diet-induced adiposity, endocrine profile, and gastrointestinal tract proliferation-associated biomarkers in male mice. PLoS ONE. (2012) 7:e46716. doi: 10.1371/journal.pone.0046716

99. Chouchani ET, Pell VR, Gaude E, Aksentijevic D, Sundier SY, Robb EL, et al. Ischaemic accumulation of succinate controls reperfusion injury through mitochondrial ROS. Nature. (2014) 515:431-5. doi: 10.1038/nature13909

100. Postic C, Girard J. Contribution of de novo fatty acid synthesis to hepatic steatosis and insulin resistance: lessons from genetically engineered mice. $J$ Clin Invest. (2008) 118:829-38. doi: 10.1172/JCI34275

101. Carmen GY, Victor SM. Signalling mechanisms regulating lipolysis. Cell Signal. (2006) 18:401-8. doi: 10.1016/j.cellsig.2005.08.009

102. Lewis GF, Carpentier A, Adeli K, Giacca A. Disordered fat storage and mobilization in the pathogenesis of insulin resistance and type 2 diabetes. Endocr Rev. (2002) 23:201-29. doi: 10.1210/edrv.23.2.0461

103. O’Neill LA, Kishton RJ, Rathmell J. A guide to immunometabolism for immunologists. Nat Rev Immunol. (2016) 16:553-65. doi: $10.1038 /$ nri.2016.70

104. Ecker J, Liebisch G, Englmaier M, Grandl M, Robenek H, Schmitz G. Induction of fatty acid synthesis is a key requirement for phagocytic differentiation of human monocytes. Proc Natl Acad Sci USA. (2010) 107:7817-22. doi: 10.1073/pnas.0912059107

105. Wu X, Dong L, Lin X, Li J. Relevance of the NLRP3 Inflammasome in the pathogenesis of chronic liver disease. Front Immunol. (2017) 8:1728. doi: 10.3389/fimmu.2017.01728

106. Csak T, Ganz M, Pespisa J, Kodys K, Dolganiuc A, Szabo G. Fatty acid and endotoxin activate inflammasomes in mouse hepatocytes that release danger signals to stimulate immune cells. Hepatology. (2011) 54:133-44. doi: 10.1002/hep.24341

107. Wree A, McGeough MD, Pena CA, Schlattjan M, Li H, Inzaugarat ME, et al. NLRP3 inflammasome activation is required for fibrosis development in NAFLD. J Mol Med. (2014) 92:1069-82. doi: 10.1007/s00109-014-1170-1

108. Dixon LJ, Berk M, Thapaliya S, Papouchado BG, Feldstein AE. Caspase1-mediated regulation of fibrogenesis in diet-induced steatohepatitis. Lab Invest. (2012) 92:713-23. doi: 10.1038/labinvest.2012.45

109. Miura K, Kodama Y, Inokuchi S, Schnabl B, Aoyama T, Ohnishi $\mathrm{H}$, et al. Toll-like receptor 9 promotes steatohepatitis by induction of interleukin-1beta in mice. Gastroenterology. (2010) 139:323-34 e7. doi: 10.1053/j.gastro.2010.03.052

110. Wahli W, Michalik L. PPARs at the crossroads of lipid signaling and inflammation. Trends Endocrinol Metab. (2012) 23:351-63. doi: 10.1016/j.tem.2012.05.001

111. Yu K, Bayona W, Kallen CB, Harding HP, Ravera CP, McMahon $\mathrm{G}$, et al. Differential activation of peroxisome proliferator-activated receptors by eicosanoids. J Biol Chem. (1995) 270:23975-83. doi: $10.1074 / j b c .270 .41 .23975$

112. Bjorndal B, Alteras EK, Lindquist C, Svardal A, Skorve J, Berge RK. Associations between fatty acid oxidation, hepatic mitochondrial function, and plasma acylcarnitine levels in mice. Nutr Metab. (2018) 15:10. doi: 10.1186/s12986-018-0241-7

113. Namgaladze D, Lips S, Leiker TJ, Murphy RC, Ekroos K, Ferreiros N, et al. Inhibition of macrophage fatty acid beta-oxidation exacerbates palmitateinduced inflammatory and endoplasmic reticulum stress responses. Diabetologia. (2014) 57:1067-77. doi: 10.1007/s00125-014-3173-4 
114. O'Connor RS, Guo L, Ghassemi S, Snyder NW, Worth AJ, Weng L, et al. The CPT1a inhibitor, etomoxir induces severe oxidative stress at commonly used concentrations. Sci Rep. (2018) 8:6289. doi: 10.1038/s41598-01824676-6

115. Pike LS, Smift AL, Croteau NJ, Ferrick DA, Wu M. Inhibition of fatty acid oxidation by etomoxir impairs NADPH production and increases reactive oxygen species resulting in ATP depletion and cell death in human glioblastoma cells. Biochim Biophys Acta. (2011) 1807:726-34. doi: 10.1016/j.bbabio.2010.10.022

116. Sheridan R, Lampe K, Shanmukhappa SK, Putnam P, Keddache M, Divanovic S, et al. Lampel: an ENU-germline mutation causing spontaneous hepatosteatosis identified through targeted exonenrichment and next-generation sequencing. PLoS ONE. (2011) 6:e21979. doi: 10.1371/journal.pone.0021979

117. Moffett JR, Namboodiri MA. Tryptophan and the immune response. Immunol Cell Biol. (2003) 81:247-65. doi: 10.1046/j.1440-1711.2003.t01-1-01177.x

118. Badawy AA, Namboodiri AM, Moffett JR. The end of the road for the tryptophan depletion concept in pregnancy and infection. Clin Sci. (2016) 130:1327-33. doi: 10.1042/CS20160153

119. McGaha TL, Huang L, Lemos H, Metz R, Mautino M, Prendergast GC, et al. Amino acid catabolism: a pivotal regulator of innate and adaptive immunity. Immunol Rev. (2012) 249:135-57. doi: 10.1111/j.1600-065X.2012.01149.x

120. Grohmann U, Bronte V. Control of immune response by amino acid metabolism. Immunol Rev. (2010) 236:243-64. doi: 10.1111/j.1600-065X.2010.00915.x

121. Hissong BD, Byrne GI, Padilla ML, Carlin JM. Upregulation of interferoninduced indoleamine 2,3-dioxygenase in human macrophage cultures by lipopolysaccharide, muramyl tripeptide, and interleukin-1. Cell Immunol. (1995) 160:264-9. doi: 10.1016/0008-8749(95)80037-J

122. Hu B, Hissong BD, Carlin JM. Interleukin-1 enhances indoleamine 2,3dioxygenase activity by increasing specific mRNA expression in human mononuclear phagocytes. J Interferon Cytokine Res. (1995) 15:617-24. doi: 10.1089/jir.1995.15.617

123. Hissong BD, Carlin JM. Potentiation of interferon-induced indoleamine 2,3-dioxygenase mRNA in human mononuclear phagocytes by lipopolysaccharide and interleukin-1. J Interferon Cytokine Res. (1997) 17:387-93. doi: 10.1089/jir.1997.17.387

124. Carlin JM, Borden EC, Sondel PM, Byrne GI. Interferon-induced indoleamine 2,3-dioxygenase activity in human mononuclear phagocytes. $J$ Leukoc Biol. (1989) 45:29-34. doi: 10.1002/jlb.45.1.29

125. Currier AR, Ziegler MH, Riley MM, Babcock TA, Telbis VP, Carlin JM. Tumor necrosis factor-alpha and lipopolysaccharide enhance interferoninduced antichlamydial indoleamine dioxygenase activity independently. $J$ Interferon Cytokine Res. (2000) 20:369-76. doi: 10.1089/107999000312306

126. Wolowczuk I, Hennart B, Leloire A, Bessede A, Soichot M, Taront S, et al. Tryptophan metabolism activation by indoleamine 2,3-dioxygenase in adipose tissue of obese women: an attempt to maintain immune homeostasis and vascular tone. Am J Physiol Regul Integr Comp Physiol. (2012) 303:R13543. doi: 10.1152/ajpregu.00373.2011

127. Nagano J, Shimizu M, Hara T, Shirakami Y, Kochi T, Nakamura $\mathrm{N}$, et al. Effects of indoleamine 2,3-dioxygenase deficiency on highfat diet-induced hepatic inflammation. PLoS ONE. (2013) 8:e73404. doi: 10.1371/journal.pone.0073404

128. Laurans L, Venteclef N, Haddad Y, Chajadine M, Alzaid F, Metghalchi $\mathrm{S}$, et al. Genetic deficiency of indoleamine 2,3-dioxygenase promotes gut microbiota-mediated metabolic health. Nat Med. (2018) 24:1113-20. doi: 10.1038/s41591-018-0060-4

129. Ritze Y, Bardos G, Hubert A, Bohle M, Bischoff SC. Effect of tryptophan supplementation on diet-induced non-alcoholic fatty liver disease in mice. Br J Nutr. (2014) 112:1-7. doi: 10.1017/S0007114514000440

130. Cichoz-Lach H, Celinski K, Konturek PC, Konturek SJ, Slomka M. The effects of L-tryptophan and melatonin on selected biochemical parameters in patients with steatohepatitis. J Physiol Pharmacol. (2010) 61:577-80.

131. Celinski K, Konturek PC, Slomka M, Cichoz-Lach H, Brzozowski T, Konturek SJ, et al. Effects of treatment with melatonin and tryptophan on liver enzymes, parameters of fat metabolism and plasma levels of cytokines in patients with non-alcoholic fatty liver disease -14 months follow up. JPhysiol Pharmacol. (2014) 65:75-82.

132. Munder M, Eichmann K, Modolell M. Alternative metabolic states in murine macrophages reflected by the nitric oxide synthase/arginase balance: competitive regulation by CD $4+\mathrm{T}$ cells correlates with Th1/Th2 phenotype. J Immunol. (1998) 160:5347-54.

133. Shearer JD, Richards JR, Mills CD, Caldwell MD. Differential regulation of macrophage arginine metabolism: a proposed role in wound healing. Am J Physiol. (1997) 272:E181-90. doi: 10.1152/ajpendo.1997.272.2.E181

134. Mattila JT, Ojo OO, Kepka-Lenhart D, Marino S, Kim JH, Eum SY, et al. Microenvironments in tuberculous granulomas are delineated by distinct populations of macrophage subsets and expression of nitric oxide synthase and arginase isoforms. J Immunol. (2013) 191:773-84. doi: 10.4049/jimmunol.1300113

135. Qualls JE, Subramanian C, Rafi W, Smith AM, Balouzian L, DeFreitas AA, et al. Sustained generation of nitric oxide and control of mycobacterial infection requires argininosuccinate synthase 1. Cell Host Microbe. (2012) 12:313-23. doi: 10.1016/j.chom.2012.07.012

136. Murray PJ, Allen JE, Biswas SK, Fisher EA, Gilroy DW, Goerdt S, et al. Macrophage activation and polarization: nomenclature and experimental guidelines. Immunity. (2014) 41:14-20. doi: 10.1016/j.immuni.2014.06.008

137. Modolell M, Corraliza IM, Link F, Soler G, Eichmann K. Reciprocal regulation of the nitric oxide synthase/arginase balance in mouse bone marrow-derived macrophages by TH1 and TH2 cytokines. Eur J Immunol. (1995) 25:1101-4. doi: 10.1002/eji.1830250436

138. Munder M, Eichmann K, Moran JM, Centeno F, Soler G, Modolell M. Th1/Th2-regulated expression of arginase isoforms in murine macrophages and dendritic cells. J Immunol. (1999) 163:3771-7.

139. Rutschman R, Lang R, Hesse M, Ihle JN, Wynn TA, Murray PJ. Cutting edge: Stat6-dependent substrate depletion regulates nitric oxide production. J Immunol. (2001) 166:2173-7. doi: 10.4049/jimmunol.166.4.2173

140. Barron L, Smith AM, El Kasmi KC, Qualls JE, Huang X, Cheever A, et al. Role of arginase 1 from myeloid cells in th2-dominated lung inflammation. PLoS ONE. (2013) 8:e61961. doi: 10.1371/journal.pone.0061961

141. Duque-Correa MA, Kuhl AA, Rodriguez PC, Zedler U, Schommer-Leitner $\mathrm{S}$, Rao $\mathrm{M}$, et al. Macrophage arginase-1 controls bacterial growth and pathology in hypoxic tuberculosis granulomas. Proc Natl Acad Sci USA. (2014) 111:E4024-32. doi: 10.1073/pnas.1408839111

142. Navarro LA, Wree A, Povero D, Berk MP, Eguchi A, Ghosh S, et al. Arginase 2 deficiency results in spontaneous steatohepatitis: a novel link between innate immune activation and hepatic de novo lipogenesis. J Hepatol. (2015) 62:412-20. doi: 10.1016/j.jhep.2014.09.015

143. Liu C, Rajapakse AG, Riedo E, Fellay B, Bernhard MC, Montani JP, et al. Targeting arginase-II protects mice from high-fat-diet-induced hepatic steatosis through suppression of macrophage inflammation. Sci Rep. (2016) 6:20405. doi: 10.1038/srep20405

144. Pasarin M, La Mura V, Gracia-Sancho J, Garcia-Caldero H, RodriguezVilarrupla A, Garcia-Pagan JC, et al. Sinusoidal endothelial dysfunction precedes inflammation and fibrosis in a model of NAFLD. PLoS ONE. (2012) 7:e32785. doi: 10.1371/journal.pone.0032785

145. Sellmann C, Degen C, Jin CJ, Nier A, Engstler AJ, Hasan Alkhatib $\mathrm{D}$, et al. Oral arginine supplementation protects female mice from the onset of non-alcoholic steatohepatitis. Amino Acids. (2017) 49:1215-25. doi: 10.1007/s00726-017-2423-4

146. Rapovy SM, Zhao J, Bricker RL, Schmidt SM, Setchell KD, Qualls JE. Differential Requirements for L-Citrulline and L-Arginine during antimycobacterial macrophage activity. J Immunol. (2015) 195:3293-300. doi: 10.4049/jimmunol.1500800

147. Lange SM, McKell MC, Schmidt SM, Zhao J, Crowther RR, Green LC, et al. L-arginine synthesis from 1-citrulline in myeloid cells drives host defense against mycobacteria in vivo. J Immunol. (2019) 202:1747-54. doi: 10.4049/jimmunol.1801569

148. Erez A, Nagamani SC, Shchelochkov OA, Premkumar MH, Campeau PM, Chen Y, et al. Requirement of argininosuccinate lyase for systemic nitric oxide production. Nat Med. (2011) 17:1619-26. doi: 10.1038/nm.2544

149. MacMicking JD, Nathan C, Hom G, Chartrain N, Fletcher DS, Trumbauer $\mathrm{M}$, et al. Altered responses to bacterial infection and endotoxic shock 
in mice lacking inducible nitric oxide synthase. Cell. (1995) 81:641-50. doi: 10.1016/0092-8674(95)90085-3

150. El Kasmi KC, Qualls JE, Pesce JT, Smith AM, Thompson RW, HenaoTamayo M, et al. Toll-like receptor-induced arginase 1 in macrophages thwarts effective immunity against intracellular pathogens. Nat Immunol. (2008) 9:1399-406. doi: 10.1038/ni.1671

151. Failla ML. Trace elements and host defense: recent advances and continuing challenges. J Nutr. (2003) 133(5 Suppl 1):1443S-7S. doi: 10.1093/jn/133.5.1443S

152. Aigner E, Theurl I, Haufe H, Seifert M, Hohla F, Scharinger L, et al. Copper availability contributes to iron perturbations in human nonalcoholic fatty liver disease. Gastroenterology. (2008) 135:680-8. doi: 10.1053/j.gastro.2008.04.007

153. Aigner E, Weiss G, Datz C. Dysregulation of iron and copper homeostasis in nonalcoholic fatty liver. World J Hepatol. (2015) 7:177-88. doi: 10.4254/wjh.v7.i2.177

154. Feldman A, Aigner E, Weghuber D, Paulmichl K. The Potential role of iron and copper in pediatric obesity and nonalcoholic fatty liver disease. Biomed Res Int. (2015) 2015:287401. doi: 10.1155/2015/287401

155. Tarantino G, Porcu C, Arciello M, Andreozzi P, Balsano C. Prediction of carotid intima-media thickness in obese patients with low prevalence of comorbidities by serum copper bioavailability. J Gastroenterol Hepatol. (2018) 33:1511-7. doi: 10.1111/jgh.14104

156. Turlin B, Mendler MH, Moirand R, Guyader D, Guillygomarc'h A, Deugnier Y. Histologic features of the liver in insulin resistance-associated iron overload. A study of 139 patients. Am J Clin Pathol. (2001) 116:263-70. doi: 10.1309/WWNE-KW2C-4KTW-PTJ5

157. Handa P, Thomas S, Morgan-Stevenson V, Maliken BD, Gochanour E, Boukhar S, et al. Iron alters macrophage polarization status and leads to steatohepatitis and fibrogenesis. J Leukoc Biol. (2019) 105:1015-26. doi: 10.1002/JLB.3A0318-108R

158. Handa P, Vemulakonda AL, Maliken BD, Morgan-Stevenson V, Nelson JE, Dhillon BK, et al. Differences in hepatic expression of iron, inflammation and stress-related genes in patients with nonalcoholic steatohepatitis. Ann Hepatol. (2017) 16:77-85. doi: 10.5604/16652681. 1226818

159. Sharp P. The molecular basis of copper and iron interactions. Proc Nutr Soc. (2004) 63:563-9. doi: 10.1079/PNS2004386

160. Himoto T, Masaki T. Associations between zinc deficiency and metabolic abnormalities in patients with chronic liver disease. Nutrients. (2018) 10:88. doi: $10.3390 /$ nu10010088

161. Trayhurn P. Hypoxia and adipose tissue function and dysfunction in obesity. Physiol Rev. (2013) 93:1-21. doi: 10.1152/physrev.00017.2012

162. Ghaben AL, Scherer PE. Adipogenesis and metabolic health. Nat Rev Mol Cell Biol. (2019) 20:242-58. doi: 10.1038/s41580-018-0093-z

163. Sarantopoulos CN, Banyard DA, Ziegler ME, Sun B, Shaterian A, Widgerow AD. Elucidating the preadipocyte and its role in adipocyte formation: a comprehensive review. Stem Cell Rev Rep. (2018) 14:27-42. doi: 10.1007/s12015-017-9774-9

164. Langin D, Dicker A, Tavernier G, Hoffstedt J, Mairal A, Ryden M, et al. Adipocyte lipases and defect of lipolysis in human obesity. Diabetes. (2005) 54:3190-7. doi: 10.2337/diabetes.54.11.3190

165. Ebbert JO, Jensen MD. Fat depots, free fatty acids, and dyslipidemia. Nutrients. (2013) 5:498-508. doi: 10.3390/nu50 20498

166. Frayn KN. Adipose tissue as a buffer for daily lipid flux. Diabetologia. (2002) 45:1201-10. doi: 10.1007/s00125-002-0873-y

167. Kamada Y, Takehara T, Hayashi N. Adipocytokines and liver disease. J Gastroenterol. (2008) 43:811-22. doi: 10.1007/s00535-0082213-6

168. O'Rourke RW, White AE, Metcalf MD, Olivas AS, Mitra P, Larison WG, et al. Hypoxia-induced inflammatory cytokine secretion in human adipose tissue stromovascular cells. Diabetologia. (2011) 54:1480-90. doi: 10.1007/s00125-011-2103-y

169. Lefere S, Van de Velde F, Devisscher L, Bekaert M, Raevens S, Verhelst $\mathrm{X}$, et al. Serum vascular cell adhesion molecule-1 predicts significant liver fibrosis in non-alcoholic fatty liver disease. Int J Obes. (2017) 41:1207-13. doi: $10.1038 /$ ijo. 2017.102
170. van Herpen NA, Schrauwen-Hinderling VB. Lipid accumulation in non-adipose tissue and lipotoxicity. Physiol Behav. (2008) 94:231-41. doi: 10.1016/j.physbeh.2007.11.049

171. Ranjit S, Boutet E, Gandhi P, Prot M, Tamori Y, Chawla A, et al. Regulation of fat specific protein 27 by isoproterenol and TNF-alpha to control lipolysis in murine adipocytes. J Lipid Res. (2011) 52:221-36. doi: 10.1194/jlr.M008771

172. Sung CK, She H, Xiong S, Tsukamoto H. Tumor necrosis factor-alpha inhibits peroxisome proliferator-activated receptor gamma activity at a posttranslational level in hepatic stellate cells. Am J Physiol Gastrointest Liver Physiol. (2004) 286:G722-9. doi: 10.1152/ajpgi.00411.2003

173. Stephens JM, Lee J, Pilch PF. Tumor necrosis factor-alpha-induced insulin resistance in 3T3-L1 adipocytes is accompanied by a loss of insulin receptor substrate-1 and GLUT4 expression without a loss of insulin receptor-mediated signal transduction. J Biol Chem. (1997) 272:971-6. doi: $10.1074 / j b c .272 .2 .971$

174. Ruan H, Hacohen N, Golub TR, Van Parijs L, Lodish HF. Tumor necrosis factor-alpha suppresses adipocyte-specific genes and activates expression of preadipocyte genes in 3T3-L1 adipocytes: nuclear factorkappaB activation by TNF-alpha is obligatory. Diabetes. (2002) 51:1319-36. doi: $10.2337 /$ diabetes.51.5.1319

175. Tilg H, Moschen AR. Adipocytokines: mediators linking adipose tissue, inflammation and immunity. Nat Rev Immunol. (2006) 6:772-83. doi: $10.1038 /$ nri1937

176. Chan CC, Damen M, Alarcon PC, Sanchez-Gurmaches J, Divanovic S. Inflammation and immunity: from an adipocyte's perspective. J Interferon Cytokine Res. (2019) 39:459-71. doi: 10.1089/jir.2019.0014

177. Zhou YJ, Zhou H, Li Y, Song YL. NOD1 activation induces innate immune responses and insulin resistance in human adipocytes. Diabetes Metab. (2012) 38:538-43. doi: 10.1016/j.diabet.2012.08.001

178. Ballak DB, van Diepen JA, Moschen AR, Jansen HJ, Hijmans A, Groenhof GJ, et al. IL-37 protects against obesity-induced inflammation and insulin resistance. Nat Commun. (2014) 5:4711. doi: 10.1038/ncomms5711

179. Zhou YJ, Liu C, Li CL, Song YL, Tang YS, Zhou H, et al. Increased NOD1, but not NOD2, activity in subcutaneous adipose tissue from patients with metabolic syndrome. Obesity. (2015) 23:1394-400. doi: 10.1002/oby.21113

180. Kopp A, Buechler C, Neumeier M, Weigert J, Aslanidis C, Scholmerich $\mathrm{J}$, et al. Innate immunity and adipocyte function: ligand-specific activation of multiple Toll-like receptors modulates cytokine, adipokine, and chemokine secretion in adipocytes. Obesity. (2009) 17:648-56. doi: 10.1038/oby.2008.607

181. Marra F, Svegliati-Baroni G. Lipotoxicity and the gut-liver axis in NASH pathogenesis. J Hepatol. (2018) 68:280-95. doi: 10.1016/j.jhep.2017.11.014

182. Frasca D, Diaz A, Romero M, Thaller S, Blomberg BB. Secretion of autoimmune antibodies in the human subcutaneous adipose tissue. PLoS ONE. (2018) 13:e0197472. doi: 10.1371/journal.pone.0197472

183. Yokota T, Oritani K, Takahashi I, Ishikawa J, Matsuyama A, Ouchi $\mathrm{N}$, et al. Adiponectin, a new member of the family of soluble defense collagens, negatively regulates the growth of myelomonocytic progenitors and the functions of macrophages. Blood. (2000) 96:1723-32. doi: 10.1182/blood.V96.5.1723

184. Hui X, Gu P, Zhang J, Nie T, Pan Y, Wu D, et al. Adiponectin enhances cold-induced browning of subcutaneous adipose tissue via promoting M2 macrophage proliferation. Cell Metab. (2015) 22:279-90. doi: 10.1016/j.cmet.2015.06.004

185. Luo Y, Liu M. Adiponectin: a versatile player of innate immunity. J Mol Cell Biol. (2016) 8:120-8. doi: 10.1093/jmcb/mjw012

186. Lappas M, Yee K, Permezel M, Rice GE. Release and regulation of leptin, resistin and adiponectin from human placenta, fetal membranes, and maternal adipose tissue and skeletal muscle from normal and gestational diabetes mellitus-complicated pregnancies. J Endocrinol. (2005) 186:457-65. doi: 10.1677/joe.1.06227

187. Tsatsanis C, Zacharioudaki V, Androulidaki A, Dermitzaki E, Charalampopoulos I, Minas V, et al. Peripheral factors in the metabolic syndrome: the pivotal role of adiponectin. Ann N Y Acad Sci. (2006) 1083:185-95. doi: 10.1196/annals.1367.013

188. Sumida Y, Yoneda M. Current and future pharmacological therapies for NAFLD/NASH. J Gastroenterol. (2018) 53:362-76. doi: $10.1007 / \mathrm{s} 00535-017-1415-1$ 
189. Munteanu MA, Nagy GA, Mircea PA. Current Management of NAFLD. Clujul Med. (2016) 89:19-23. doi: 10.15386/cjmed-539

190. Friedman SL, Neuschwander-Tetri BA, Rinella M, Sanyal AJ. Mechanisms of NAFLD development and therapeutic strategies. Nat Med. (2018) 24:908-22. doi: 10.1038/s41591-018-0104-9

191. Wang CH, Weisel RD, Liu PP, Fedak PW, Verma S. Glitazones and heart failure: critical appraisal for the clinician. Circulation. (2003) 107:1350-4. doi: 10.1161/01.CIR.0000054675.30348.9A

192. Nesto RW, Bell D, Bonow RO, Fonseca V, Grundy SM, Horton ES, et al. Thiazolidinedione use, fluid retention, and congestive heart failure: a consensus statement from the American Heart Association and American Diabetes Association. Diabetes Care. (2004) 27:256-63. doi: $10.2337 /$ diacare.27.1.256

193. Komiya C, Tsuchiya K, Shiba K, Miyachi Y, Furuke S, Shimazu N, et al. Ipragliflozin improves hepatic steatosis in obese mice and liver dysfunction in type 2 diabetic patients irrespective of body weight reduction. PLOS ONE. (2016) 11:e0151511. doi: 10.1371/journal.pone.0151511

194. Takase T, Nakamura A, Miyoshi H, Yamamoto C, Atsumi T. Amelioration of fatty liver index in patients with type 2 diabetes on ipragliflozin: an association with glucose-lowering effects. Endocr J. (2017) 64:363-7. doi: 10.1507/endocrj.EJ16-0295

195. Brenner C, Galluzzi L, Kepp O, Kroemer G. Decoding cell death signals in liver inflammation. J Hepatol. (2013) 59:583-94. doi: 10.1016/j.jhep.2013.03.033

196. Wang PX, Ji YX, Zhang XJ, Zhao LP, Yan ZZ, Zhang P, et al. Targeting CASP8 and FADD-like apoptosis regulator ameliorates nonalcoholic steatohepatitis in mice and nonhuman primates. Nat Med. (2017) 23:439-49. doi: $10.1038 / \mathrm{nm} .4290$

197. Yamamoto E, Dong YF, Kataoka K, Yamashita T, Tokutomi Y, Matsuba S, et al. Olmesartan prevents cardiovascular injury and hepatic steatosis in obesity and diabetes, accompanied by apoptosis signal regulating kinase-1 inhibition. Hypertension. (2008) 52:573-80. doi: 10.1161/HYPERTENSIONAHA.108.112292

198. Farrell G, Schattenberg JM, Leclercq I, Yeh MM, Goldin R, Teoh N, et al. Mouse models of nonalcoholic steatohepatitis: toward optimization of their relevance to human nonalcoholic steatohepatitis. Hepatology. (2019) 69:2241-57. doi: 10.1002/hep.30333

199. Loomba R, Lawitz E, Mantry PS, Jayakumar S, Caldwell SH, Arnold $\mathrm{H}$, et al. The ASK1 inhibitor selonsertib in patients with nonalcoholic steatohepatitis: a randomized, phase 2 trial. Hepatology. (2018) 67:549-59. doi: 10.1002/hep.29514

200. Giles DA, Moreno-Fernandez ME, Stankiewicz TE, Graspeuntner S, Cappelletti M, Wu D, et al. Thermoneutral housing exacerbates nonalcoholic fatty liver disease in mice and allows for sex-independent disease modeling. Nat Med. (2017) 23:829-38. doi: 10.1038/nm.4346

201. Yanguas SC, Cogliati B, Willebrords J, Maes M, Colle I, van den Bossche B, et al. Experimental models of liver fibrosis. Arch Toxicol. (2016) 90:1025-48. doi: $10.1007 /$ s00204-015-1543-4

Conflict of Interest: The authors declare that the research was conducted in the absence of any commercial or financial relationships that could be construed as a potential conflict of interest.

Copyright (C) 2019 Oates, McKell, Moreno-Fernandez, Damen, Deepe, Qualls and Divanovic. This is an open-access article distributed under the terms of the Creative Commons Attribution License (CC BY). The use, distribution or reproduction in other forums is permitted, provided the original author(s) and the copyright owner(s) are credited and that the original publication in this journal is cited, in accordance with accepted academic practice. No use, distribution or reproduction is permitted which does not comply with these terms. 